\title{
Isothiazoles in the Design and Synthesis of Biologically Active Substances and Ligands for Metal Complexes
}

\author{
Alexey V. Kletskov*a (iD) \\ Nikolay A. Bumagin ${ }^{b}$ \\ Fedor I. Zubkova (D) \\ Dmitry G. Grudinin ${ }^{a}$ \\ Vladimir I. Potkinc \\ a Organic Chemistry Department, Faculty of Science, Peoples' Friendship \\ University of Russia (RUDN University), 6 Miklukho-Maklaya St., Moscow \\ 117198, Russian Federation \\ avkletskov@gmail.com \\ ${ }^{\mathrm{b}}$ M.V. Lomonosov Moscow State University, Leninskii Gory, 1/3, Moscow \\ 119991, Russian Federation \\ bna51@mail.ru \\ ' Institute of Physical Organic Chemistry, National Academy of Sciences \\ of Belarus, Surganova Str., 13, 220072, Minsk, Belarus \\ potkin@ifoch.bas-net.by
}

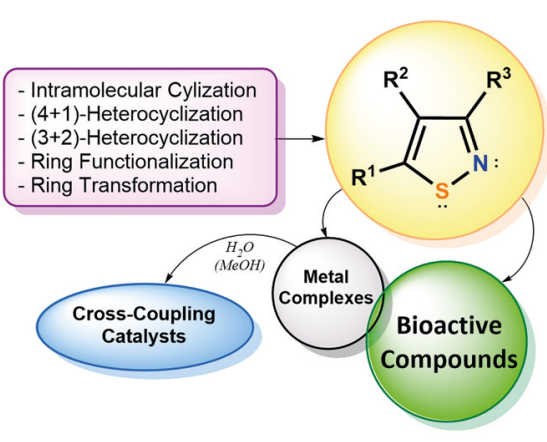

\section{Introduction}

Accepted after revision: 09.09.2019

Published online: 17.10 .2019

DOI: 10.1055/s-0039-1690688; Art ID: ss-2019-z0406-r

License terms: (c)

(c) 2020. The Author(s). This is an open access article published by Thieme under the terms of the Creative Commons Attribution License, permitting unrestricted use, distribution and reproduction, so long as the original work is properly cited. (https://creativecommons.org/licenses/by/4.0/)

Abstract The chemistry of isothiazoles is being intensively developed, which is evidenced by the wide range of selective transformations involving the isothiazole heterocycle and the high biological activity of its derivatives that can be used as effective new drugs and plant protection chemicals. Some representatives of isothiazoles have proven to be synergists of bioactive substances, which opens the way to lower the doses of drugs used and is especially important in cancer chemotherapy. In the framework of the present review, the accomplishments in the chemistry of isothiazoles over the past 18 years are examined, whilst current strategies for the synthesis of isothiazole-containing molecules and key directions of studies in this field of heterocyclic chemistry are discussed. Considerable attention is paid to chlorinated isothiazoles and strategies for their use in the synthesis of biologically active substances. In addition, a comprehensive review of existing literature in the field of metal complexes of isothiazoles is given, including the results and prospects for the practical use of isothiazole-metal complexes as catalysts for cross-coupling reactions in aqueous and aqueous-alcoholic media ('green chemistry').

Introduction

Synthesis by Ring-Forming Reactions

2.1 Intramolecular Cyclization

2.2 (4+1)-Heterocyclization

2.3 (3+2)-Heterocyclization

2.4 Syntheses by Ring Transformations

3 Isothiazoles by Ring Functionalization Reactions: Nucleophilic Substitution, Cross-Coupling and Side-Chain Functionalization

4 Selected Syntheses of Biologically Active Isothiazole Derivatives

5 Isothiazoles in the Synthesis of Transition-Metal Complexes and in Metal-Complex Catalysis

6 Conclusion

Key words heterocycles, isothiazoles, bioactive heterocycles, catalysis, cross-coupling, palladium, transition metals, complexes
The search for new chemical compounds with useful properties and the development of rational ways to synthesize them are priority tasks in chemical science, with the synthesis of biologically active chemical compounds for medicine and agriculture being of particular importance. In this respect, isothiazole derivatives, which have demonstrated high potential in the design and synthesis of a wide range of biologically active substances, are of great interest. Among natural bioregulators, isothiazole-containing compounds are present in only a few examples: the phytoalexins (brassilexin ${ }^{1}$ and sinalexin), ${ }^{2}$ a prostaglandin release inhibitor (pronkodin A), ${ }^{3}$ and a cytotoxin (aulosirazol). ${ }^{4} \mathrm{How}-$ ever, this does not impede the use of the isothiazole nucleus in the creation of a wide variety of bioactive substances; for example, compounds exhibiting anti-poliovirus activity have been synthesized. ${ }^{5}$ Promising compounds for the treatment of Parkinson's disease have also been identified, ${ }^{6}$ and recently, derivatives suitable for cancer $^{7-12}$ and diabetes $^{13-15}$ therapy have been obtained, as well as microbicides. $^{16,17}$ The isothiazole heterocycle in microbicides can protect the molecule from the action of enzymes, ${ }^{18,19}$ thereby extending the time of the molecule's action, which in turn makes it possible to administer additional doses of the drug less frequently. A promising class of isothiazole-containing inhibitors of the nuclear bile acid receptor FXR has been found, representatives of which can be used in the treatment of liver diseases. ${ }^{20}$ Some isothiazoles can be successfully used to create competitive antagonists of insect GABA receptors, ${ }^{21}$ and among the isothiazoles, effective plant growth regulators ${ }^{22}$ and fungicides ${ }^{23,24}$ have been found. 


\section{Biographical Sketches}
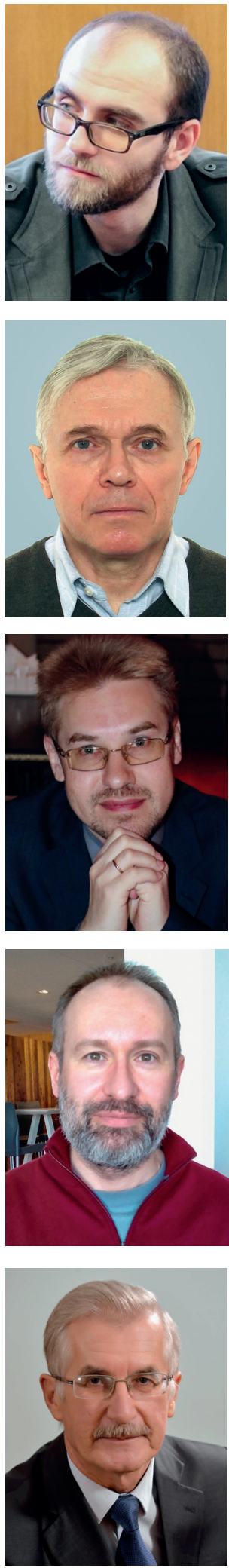

Alexey Viktorovich Kletskov

obtained his Master's degree from the Graduate School of the National Academy of Sciences of Belarus in 2013, and subsequently received his Ph.D. in 2017 from the Institute of Physical Organic Chemistry, National

Nikolay Alexandrovich Bumagin received his Ph.D. in 1979 and his D.Sc. degree in 1986 from M.V. Lomonosov Moscow State University. He was awarded the Nesmeyanov

Fedor Ivanovich Zubkov earned his Master's degree in chemistry at the Peoples' Friendship University of Russia in 1997, followed by his Ph.D. in
Academy of Sciences of Belarus. $\mathrm{He}$ is currently a postdoctoral researcher at the Department of Organic Chemistry at RUDN University (Russia). His current scientific interests include the development of novel synthetic methodologies in the field of heterocyclic chemistry, the synthesis and study of metal complexes with substituted isothiazoles and isoxazoles, and the synthesis of novel heterocyclic substances with high potential for practical applications.
Prize in 1991 and earned the title of Professor in 1992. He is currently Head of the Transition Metal Catalysis Group at the Department of Chemistry of Moscow State University. His current scientific interests are focused on homo- and heterogeneous catalysis in organic synthesis, the chemistry of heterocyclic compounds, and green chemistry. chemistry in 2000. From 2001 until present, he has worked as a docent at the Organic Chemistry Department of the Peoples' Friendship University of Russia.
His scientific interests include cycloaddition reactions, transformations of oxygen- and nitrogen-containing heterocycles, and total synthesis.
Dmitry Guennadievich Grudinin earned his Ph.D. in chemistry at the Peoples' Friendship University of Russia in 2000. Since 2001 he has worked for

Vladimir Ivanovich Potkin graduated from Gorky State University (now Nizhny Novgorod, Russia) in 1975. He received his Ph.D. in 1982 from the Institute of Physical Organic Chemistry of the Belorussian Academy of Sciences, and his D.Sc. in 1996 from Belarusian chemical and pharmaceutical companies in Russia, South Korea, and Canada. His scientific interests include the synthesis of heterocyclic compounds and new organic materials for electronics, as well as pharmaceutical analysis.
State University. In 2000 he was elected as a Corresponding Member of the National Academy of Sciences of Belarus, and in 2009 he earned the title of Professor of Chemistry. Currently, he is the Head of the Organic Chemistry Department at the Institute of Physical Organic
Chemistry, National Academy of Sciences of Belarus. His scientific interests include heterocyclic chemistry, the synthesis and study of biologically active compounds, and metal complexes of isothiazoles and isoxazoles and their properties. 
In a few reports, isothiazoles have been studied for possible use as ligands for metal complexes. At the same time, despite the fact that metal complexes in general have proven themselves useful in creating a wide range of new technologies and biologically active substances, ways to apply isothiazole complexes in practice have rarely been investigated. Some recent publications, in which the promise of using metal complexes of isothiazole for the catalysis of organic reactions and the development of pesticides has been shown, ${ }^{25-27}$ are the exception.

The above facts demonstrate the high potential of using isothiazole heterocycles in the design and synthesis of compounds for different purposes and indicate broad prospects for the further development of isothiazole chemistry, especially coordination chemistry. Within the framework of the present review, achievements in isothiazole chemistry over the past 18 years will be covered, and references from previous years will be mentioned only to create a holistic picture of the recent research progress in this field.

This review deliberately does not include data on isothiazolinones, 1,1-isothiazoledioxides, and dihydroisothiazoles, and only some examples related to condensed isothiazole-containing systems are considered. This is due to the fact that, in our opinion, such compounds, although being related, differ significantly in their chemical properties from 1,2-thiazole, and a consideration of their chemical transformations as well as their practical use would lead to a significant increase in the volume of this paper and distract from the subject being reviewed. However, special attention is paid to halogen-containing isothiazoles, and in particular, chlorinated isothiazoles, which are convenient synthetic building blocks that allow the ability to obtain a wide variety of substituted isothiazoles capable of acting both as biologically active substances and as ligands for metal complexes.

In the general context of the chemistry of heterocyclic compounds, data on the chemical properties of isothiazoles are presented in review articles, ${ }^{28-30}$ whilst isothiazoles have been directly reviewed, ${ }^{31-34}$ and covered in a monograph $^{35}$ devoted to biologically active isothiazoles. There are also reports summarizing data on isothiazole-ring-containing compounds in crop protection, ${ }^{36}$ the involvement of the isothiazole core in cross-coupling reactions, ${ }^{37}$ and [4+2] cycloadditions of isothiazole derivatives. ${ }^{38}$

There are a significant number of methods for isothiazole synthesis, and so in order to present the material consistently as well as to form a holistic view of isothiazole chemistry, it would be rational to first consider the approaches to isothiazole cycle design, highlighting the main synthetic strategies. Next, some methods for the functionalization of isothiazoles will be reviewed, and after that, targeted syntheses of biologically active agents that are promising for practical use will be considered. The available information on metal complexes with isothiazole ligands is considered in the final part of the literature review, and will, in our opinion, provide a comprehensive picture of developments in the field of isothiazole metal complexes, including information that has escaped the attention of other authors for one reason or another.

\section{Synthesis by Ring-Forming Reactions}

Different approaches can be used to classify the methods for producing isothiazoles, and the classification proposed herein by us is based on retrosynthetic analysis. This allows us to build a consistent and logical understanding of the approaches to the production of substituted isothiazoles, and in some cases, to provide the most rational methods for their synthesis. However, the predictive efficiency of this retrosynthetic classification is low in the case of complex reactions with an unobvious mechanism, as the proposed classification does not always reflect the true mechanism of the reaction. Yet, it does allow us to visualize the possible conditions for the preparation of isothiazoles, representing the formation of an isothiazole ring from fragments containing a certain number of atoms. It certainly does not cover all possible methods for the preparation of substituted isothiazoles, but it reflects the key stages of most approaches to their synthesis. Overall, retrosynthetic analysis allows us to distinguish four rational approaches for the formation of the isothiazole ring.

\subsection{Intramolecular Cyclization}

An example of such an approach is the synthesis of substituted isothiazoles $\mathbf{1}$ by forming an S-N bond in an S-C$\mathrm{C}-\mathrm{C}-\mathrm{N}$ fragment via oxidative cyclization of substituted 3aminopropenethiones $\mathbf{2}$ under the action of various reagents. The classic version of this approach uses iodine; ${ }^{39}$ however, methods using other oxidizing agents, such as hydrogen peroxide, have recently become very popular (Scheme 1). ${ }^{40,41}$ Hydrogen peroxide, in particular, was used in the formation of the isothiazole nucleus at the penultimate stage in the synthesis of a series of allosteric antagonists of the mGluR1 receptor, and which are promising compounds for the treatment of various pain syndromes. ${ }^{40}$

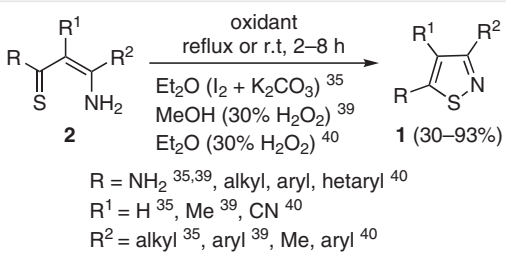

Scheme 1 Synthesis of isothiazoles through oxidative cyclization of substituted 3-aminopropenethiones 
Along with iodine, bromine can be used for effective oxidative cyclization. Thus, the isothiazoles $\mathbf{4}$, which are inhibitors of hepatitis C polymerase NS5B as well as precursors of the inhibitors of the important cancer therapy kinases Chk2 and MEK1, have been synthesized by oxidizing $\mathrm{N}$-substituted propanethioamides with molecular bromine in ethyl acetate (Scheme 2).42-44

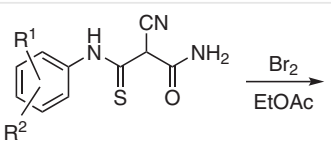

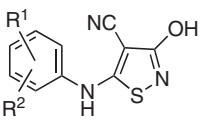

$4(70-90 \%)$
Scheme 2 Bromine as the efficient reagent for cyclization of 3-aminopropenethiones

From a preparative point of view, a promising variation of this approach is the oxidation of isothiazole precursors without the use of a solvent. Thus, it has been shown that the solvent-free oxidative cyclization of 3-aminopropenethiones $\mathbf{5}$ can be carried out by using chromium trioxide supported on silica gel (Scheme 3). ${ }^{45}$ It should be noted that the yields of the corresponding 4-cyanoisothiazoles 6 did not depend on whether the reaction was performed at room temperature for 2-3 hours, or for 1-2 minutes under microwave irradiation.

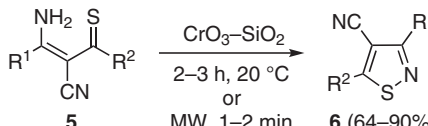

$$
\begin{aligned}
& \mathrm{R}^{1}=\mathrm{Me}, \mathrm{Ph}, 4-\mathrm{MeC}_{6} \mathrm{H}_{4} \\
& \mathrm{R}^{2}=\text { alkyl, }-\mathrm{CH}_{2} \mathrm{OPh},-\mathrm{CH}_{2}-\left(2,4-\mathrm{Cl}_{2} \mathrm{C}_{6} \mathrm{H}_{3}\right) \\
& \text { 2-thienyl, 2-furyl }
\end{aligned}
$$

Scheme 3 Oxidative ring closure of 3-aminopropenethiones under $\mathrm{CrO}_{3} / \mathrm{SiO}_{2}$ system action

The closure of the $\mathrm{C}-\mathrm{N}-\mathrm{S}-\mathrm{C}-\mathrm{C}$ fragment with the formation of a $\mathrm{C}-\mathrm{C}$ bond can serve as another interesting example of intramolecular cyclization. Using this approach, the formation of an isothiazole ring in the synthesis of the VEGFR1 and VEGFR2 inhibitors was carried out. ${ }^{46}$ The intramolecular condensation of an activated methylene fragment with a cyano group in compounds $\mathbf{7}$ led to isothiazoles $\mathbf{8}$, of which further directed modification allowed the target compounds to be obtained (Scheme 4).

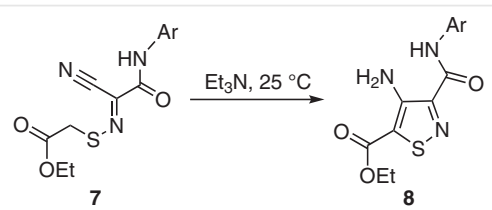

Scheme 4 Formation of isothiazole core through nucleophilic cyclization in the 4-aminoisothiazole synthesis

As an important example of the formation of the isothiazole nucleus by the closure of a five-membered fragment, a recently proposed method for the synthesis of reactive 3chloroisothiazole $(\mathbf{9})$ should be mentioned. The 3,3'-disulfanyldipropanoic acid diamide $\mathbf{1 0}$ can be cyclized to give 3chloroisothiazole (9) by the action of phosphorus oxychloride in toluene (Scheme 5). ${ }^{47}$

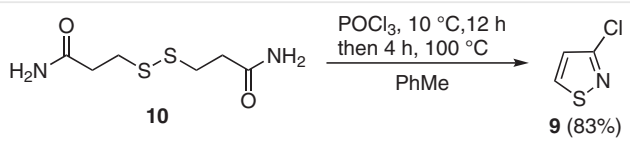

Scheme 5 Preparation of 3-chloroisothiazole from the 3,3'-disulfanyldipropanoic acid diamide

\section{2 (4+1)-Heterocyclization}

In the framework for this approach, we can consider the heterocyclization of synthetic equivalents of synthons, which are formed when one atom is removed from the isothiazole ring, with the synthetic equivalents of the corresponding atom. The most relevant examples of the heterocyclization of compounds corresponding to synthons with one heteroatom removed from a 1,2-thiazole ring are given below.

Recently, an original method for producing substituted furo[2,3-c]isothiazoles $\mathbf{1 1}$ from 2-[amino(3-aryl-2-cyanooxiran-2-yl)methylene]malononitriles 12 in an aqueous dioxane medium with sodium thiocyanate as a sulfur donor was described (Scheme 6) ${ }^{48}$ It is noteworthy that in previous studies the only proposed method for the synthesis of furo[2,3-c]isothiazoles was via intramolecular nucleophilic substitution with the participation of azide and thione fragments. ${ }^{49,50}$

It was found that an $\mathrm{S}_{2} \mathrm{Cl}_{2}$ molecule can act as a sulfur donor in the synthesis of isothiazoles, as was shown when preparing dinitrobenzo[c]isothiazole 13 from 2-amino-4,6dinitrotoluene (14) (Scheme 7). ${ }^{51}$ The key value of the

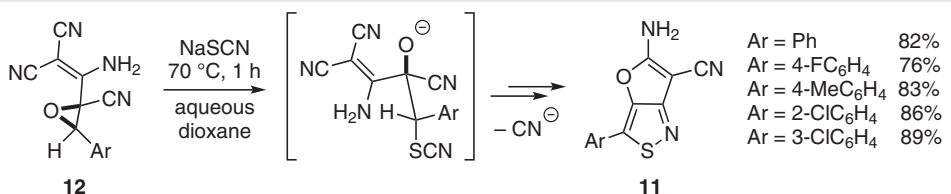

Scheme 6 Formation of furo[2,3-c] isothiazoles through rearrangement of substituted cyanooxirans 
<smiles>O=[N+]([O-])c1cc([N+](=O)[O-])c([N+](=O)[O-])cc1[N+](=O)[O-]</smiles>

14

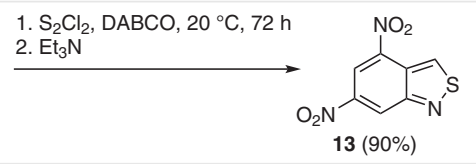

Scheme 7 Sulfur dichloride as the reagent for construction of benzo[c]isothiazole

nature of the base used in the first stage of the reaction was revealed: when $\mathrm{N}$-ethyldiisopropylamine or triethylamine were used individually, the yield of the desired isothiazole 13 did not exceed $18 \%$. However, with the sequential introduction of 1,4-diazabicyclo[2.2.2] octane (DABCO), and then triethylamine, a $90 \%$ yield of isothiazole 13 was achieved.

A recently proposed method for the synthesis of 3,4-dichloroisothiazole-5-carbonitrile (15) from succinonitrile (16), sulfur, and chlorine gas is of considerable industrial interest (Scheme 8)..$^{52}$ The method avoids the use of aprotic polar solvents such as DMF, which increase the cost of production and at the same time increase the environmental hazards. Nitrile $\mathbf{1 5}$ is not only a representative of a reactive class of chlorinated isothiazoles but is also a precursor of 3,4-dichloroisothiazole-5-carboxylic acid 2-cyanoanilide, also known as isotianil, a commercial fungicide.

$$
\stackrel{\mathrm{NC}}{\stackrel{\mathrm{S}, \mathrm{Cl}_{2}, 120-125^{\circ} \mathrm{C}, 22 \mathrm{~h}}{\longrightarrow}}
$$

Scheme 8 Synthesis of the isotianil precursor

Recently, 3,5-aryl-substituted isothiazoles $\mathbf{1 7}$ have been synthesized based on unsaturated $\mathrm{N}$-sulfonyl ketimines $\mathbf{1 8}$, via the cascade addition of an $\mathrm{S}_{3}{ }^{-}$radical anion and subsequent reductive detosylation (Scheme 9). ${ }^{53}$ The lowest yield $(14 \%)$ was observed for the thienyl derivative $\left(R^{1}=2\right.$-thienyl, $\left.\mathrm{R}^{2}=4-\mathrm{MeC}_{6} \mathrm{H}_{4}\right)$.

$$
\overbrace{R^{1}}^{N^{-T S}}
$$

18

$$
\begin{gathered}
\mathrm{K}_{2} \mathrm{~S} \text { (2 equiv) } \\
\underset{\mathrm{K}_{2} \mathrm{CO}_{3}(0.5 \text { equiv), } 0.5 \mathrm{~h}}{\mathrm{DMF}, 130^{\circ} \mathrm{C}, \text { air }} \\
\mathrm{R}^{1}=\mathrm{Ar}, 2 \text {-thienyl; } \mathrm{R}^{2}=\mathrm{Ar}
\end{gathered}
$$

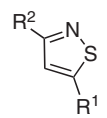

$17(14-51 \%)$
Scheme 9 A route to 3,5-diarylisothiazoles via the cyclization of ketimines

A new protocol for the synthesis of 3,5-disubstituted/annulated isothiazoles $\mathbf{1 9}$ utilizing $\beta$-keto dithioesters/ $\beta$-keto thioamides $\mathbf{2 0}$ and $\mathrm{NH}_{4} \mathrm{OAc}$ under metal-free conditions was reported in 2016 (Scheme 10)..$^{54}$ The strategic (4+1) annulation initiated by $\mathrm{NH}_{4} \mathrm{OAc}$ is carboneconomic and relies on a sequential imine formation/ cyclization/aerial oxidation cascade forming consecutive $\mathrm{C}-\mathrm{N}$ and $\mathrm{S}-\mathrm{N}$ bonds in one pot.

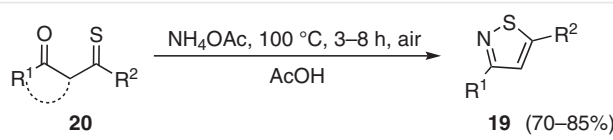

Scheme 10 Use of $\beta$-keto thioesters for 3,5-disubstituted isothiazole synthesis

Substituted isothiazoles $\mathbf{2 1}$ were able to be isolated as minor products when $\beta$-keto dithioesters $\mathbf{2 2}$ were reacted with ammonia, which also acts as a donor of the nitrogen atom to construct a 1,2-thiazole heterocycle. Additionally, it was found that copper acetate promotes formation of the isothiazole heterocycle (Scheme 11). ${ }^{55}$

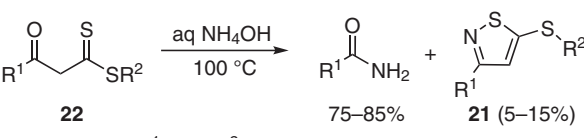

$$
\begin{aligned}
& \mathrm{R}^{1}=\mathrm{Ar} ; \mathrm{R}^{2}=\mathrm{Me}, \mathrm{Et}
\end{aligned}
$$

Scheme 11 Short pathway to 5-thioisothiazoles

\section{$2.3(3+2)$-Heterocyclization}

This approach involves the interaction of two chemical compounds that act as suppliers of diatomic and triatomic fragments to form an isothiazole ring.

Recently, a series of 4-arylisothiazoles $\mathbf{2 4}$, as inhibitors of the detoxification of the isothiazole-containing brassilexin fungicide in $L$. maculans fungus, was synthesized using this approach. Thus, the corresponding $\alpha, \beta$-unsaturated aldehydes $\mathbf{2 3}$ were introduced into the reaction with ammonium thiocyanate in dimethylformamide to give the 4arylisothiazoles $\mathbf{2 4}$ (Scheme 12). ${ }^{56}$ The ammonium thiocyanate in the reaction acts as a donor of the $\mathrm{N}-\mathrm{S}$ fragment.

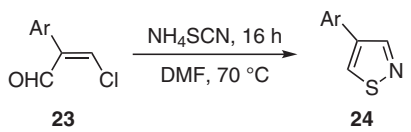

$\mathrm{Ar}=\mathrm{Ph}(54 \%), 2-\mathrm{ClC}_{6} \mathrm{H}_{4}(30 \%), 2-\mathrm{MeC}_{6} \mathrm{H}_{4}(25 \%)$

Scheme 12 Heterocyclization of 3-chloroacroleins under $\mathrm{NH}_{4} \mathrm{SCN}$ action

According to a similar scheme, isothiazoles 25 were obtained from (Z)-3,4-diaryl-3-chloroacrylaldehydes 26. Compounds 25 demonstrate inhibitory activity against COX-1 and COX-2 cyclooxygenases, 5-LOX lipoxygenase, ${ }^{57}$ and potentially against mitogen-activated $\mathrm{p} 38 \alpha$ protein kinase. They are also considered as promising candidates for in vitro and in vivo testing for anti-neuroinflammatory activity and neuroprotective properties (Scheme 13). ${ }^{58}$ 


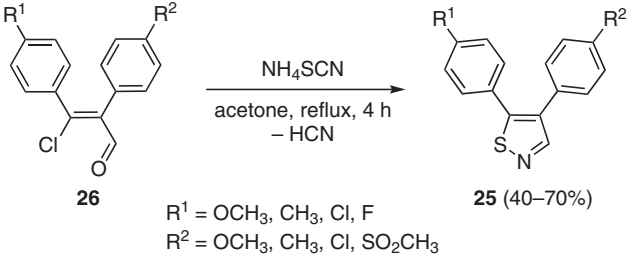

Scheme 13 3-Chloroacrylaldehydes in the synthesis of arylisothiazoles

The 1,3-dipolar cycloaddition reaction, also known as the Huisgen cycloaddition, represents another method that can be used for isothiazole cycle formation and should be mentioned within the framework of the regarded approach. The reaction of functionalized acetylenes with nitrile sulfides-reactive dipoles generated from 2-oxo-1,3,4-oxathiazoles in aprotic polar solvents such as chlorobenzene and toluene-can serve as an example. In particular, 3-phenylisothiazol-5-carboxylic acid 27a and 3-phenylisothiazole-4carboxylic acid 27b were obtained from phenyloxathiazolone 28 by this method (Scheme 14), and the synthesized products showed low in vitro cytotoxicity along with the ability to protect cells from being infected with HIV-1. ${ }^{59}$

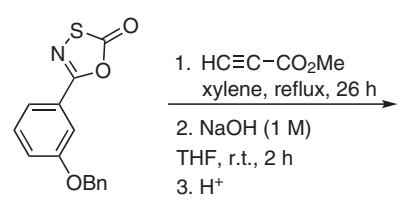

28

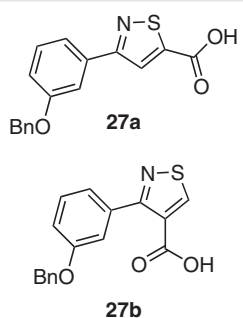

Scheme 14 The cycloaddition reaction between 2-oxo-1,3,4-oxathiazole and methyl propiolate

The efficiency of using microwave irradiation in such reactions has been demonstrated. This method allows avoiding long reaction times and, in some cases, reduces the amount of by-products and increases the yields of the target compounds. ${ }^{60}$ Thus, phenyloxothiazolone $\mathbf{2 9}$ was reacted with dimethyl acetylenedicarboxylate (DMAD) in chloroform under microwave irradiation to form adduct $\mathbf{3 0}$ in a yield of 56\%, while the reaction with propiolic acid ethyl ester (EP) for 10 minutes resulted in a mixture of regioisomeric isothiazoles 31a and 31b with a total yield of $48 \%$ (Scheme 15). The authors noted that a low level of regioselectivity was a common factor for reactions of nitrile sulfides, in contrast to reactions of nitrile oxides, which led to isoxazole-5-carboxylates as the main products. This effect is usually attributed to a higher degree of HOMO-dipole control for nitrile sulfide reactions.

Finally, a very interesting and original example of $(3+2)-$ heterocyclization is the recently proposed method of asymmetric synthesis of condensed isothiazoles 32 through a

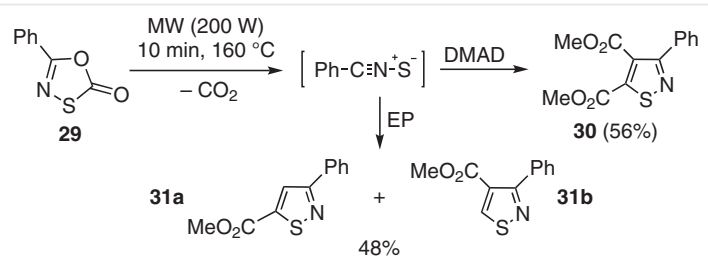

Scheme 15 Phenyloxothiazolone reaction with ethyl propiolate and DMAD under microwave irradiation

copper-catalyzed direct asymmetric conjugate addition of allyl cyanide (33) to $\alpha, \beta$-unsaturated thioamides 34 (Scheme 16). ${ }^{61}$

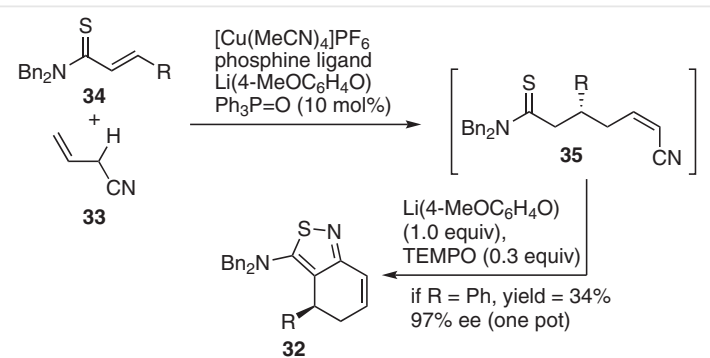

Scheme 16 An example of an asymmetric cyclocondensation resulting in isothiazoles

It is important to note that the yield of the target isothiazoles 32a-d increased with the introduction of preliminary isolated products of the allyl cyanides addition $\mathbf{3 5}$ to $\alpha, \beta$-unsaturated thioamides into the reaction (Scheme 17).

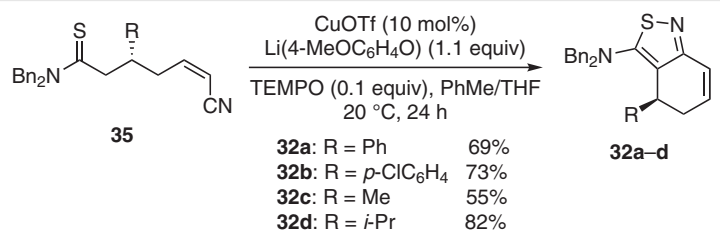

Scheme 17 Optimal conditions for the asymmetric synthesis of isothiazoles

\subsection{Syntheses by Ring Transformations}

Formally, reactions for the synthesis of substituted isothiazoles on the basis of other heterocycles can be considered within the framework of the three previous approaches, since they usually proceed through the stage of breaking the bonds in the initial cyclic molecule and subsequent heterocyclization of the resulting intermediate. However, in our opinion, it is advisable to single out the reactions that result in the transformation of other heterocycles into isothiazoles as a separate approach. This is due, first of all, to the rather complicated mechanism of such reactions, and to a certain non-obviousness in choosing possible synthetic equivalents when analyzing the structures of the desired isothiazoles. 


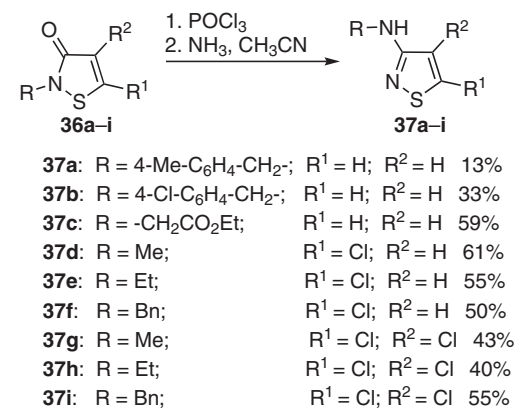

Scheme 18 Preparation of 3-aminoisothiazoles on the base of 3-isothiazolones

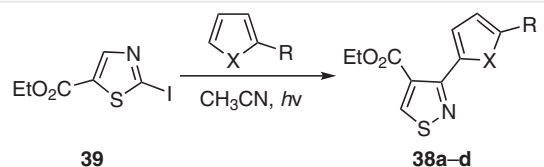

38a: $X=S, R=H(96 \%, 10: 1$ isomers of 2- and 3-subsituted thiophene)

38b: $X=S, R=B r(36 \%) ; 38 c: X=-C H=C H-, R=H(90 \%) ; 38 d: X=O, R=H(89 \%)$

Scheme 19 The tandem photoarylation/photoisomerization of 2-iodothiazole-5-carboxylic ethyl ester

An important example of this approach is the synthesis of isothiazoles based on N-substituted 3-isothiazolones. 3Isothiazolones 36a-i can be transformed into functionalized 3-aminoisothiazoles $\mathbf{3 7 a - i}$ by sequential treatment with phosphoryl chloride and ammonia (Scheme 18). ${ }^{62}$

Among the methods for the synthesis of isothiazoles based on other heterocycles, the recently proposed method for the synthesis of 3-phenyl(heteroaryl)isothiazole-3-carboxylic acid ethyl esters 38a-d via the tandem photoarylation and photoisomerization of 2-iodothiazole-5-carboxylic acid ethyl ester 39 is of considerable interest (Scheme 19). ${ }^{63}$ It should be noted that no rearrangement occurred in the case of a similar 2-chloro-substituted thiazole.

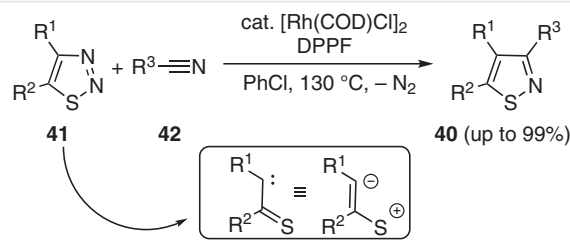

$\mathrm{R}^{1}=\mathrm{CO}_{2} \mathrm{Et}, \mathrm{Ph} ; \mathrm{R}^{2}=\mathrm{CO}_{2} \mathrm{Et}, \mathrm{Ar} ; \mathrm{R}^{3}=$ alkyl, aryl, hetaryl

Scheme 20 Rhodium-catalyzed transannulation of 1,2,3-thiadiazoles
Recently, an original method for the synthesis of 3,4,5functionalized isothiazoles $\mathbf{4 0}$ was developed through rhodium-catalyzed transannulation of 1,2,3-thiadiazoles $\mathbf{4 1}^{\text {64 }}$ with alkyl, aryl, and hetaryl nitriles $\mathbf{4 2}$ through the formation of a rhodium $\alpha$-thiavinyl carbenoid. The authors suggest that in the reaction with nitriles, the $\alpha$-thiavinyl carbenoid acts as an equivalent of a 1,3-dipole with reversed polarity (Scheme 20).

Later, this method was successfully used by the same authors to synthesize a series of bi-, tri-, and tetracyclic isothiazoles $\mathbf{4 3}$ with good to excellent yields through the intramolecular transannulation of cyanothiadiazoles $\mathbf{4 4}$ (Scheme 21). ${ }^{65}$

Isothiazoles can be obtained on the basis of 1,2,3-dithiazoles. Recently, improved conditions for the ring transformation of 1,2,3-dithiazoles 45 into isothiazole-5-carbonitriles 46 were reported (Scheme 22). ${ }^{66}$ Shorter reaction times correlated with higher isothiazole yields and the use of THF as solvent in almost all cases.

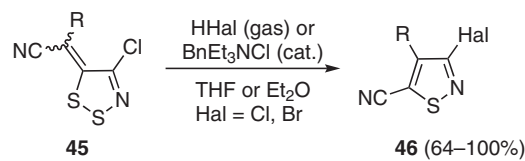

$\mathrm{R}=\mathrm{H}, \mathrm{Cl}, \mathrm{Br}, \mathrm{CO}_{2} \mathrm{Me}, \mathrm{CO}_{2} \mathrm{Et}, \mathrm{CN}$

Scheme 22 Preparation of 5-cyanoisothiazoles through the acidcatalyzed RORC reaction

\section{Isothiazoles by Ring Functionalization Reactions: Nucleophilic Substitution, Cross- Coupling and Side-Chain Functionalization}

Next, we will consider some methods for the synthesis of isothiazoles in which reagents containing the formed isothiazole ring are involved. The chemical properties of isothiazoles are largely defined by the presence of the delocalized $\pi$-orbitals system. Isothiazoles have a high degree of aromaticity in accordance with the HOMA (harmonic oscillator model of aromaticity) criterion. In this respect, among the 1,2-azoles, isothiazoles occupy an intermediate position between isoxazole and pyrazole, being much more aromatic than isoxazoles, but less so than pyrazoles. Isothiazole derivatives are also more aromatic than thiazole derivatives. Positions 3 and 5 of the isothiazole ring are favorable for the attack of nucleophilic reagents, while position 4 is

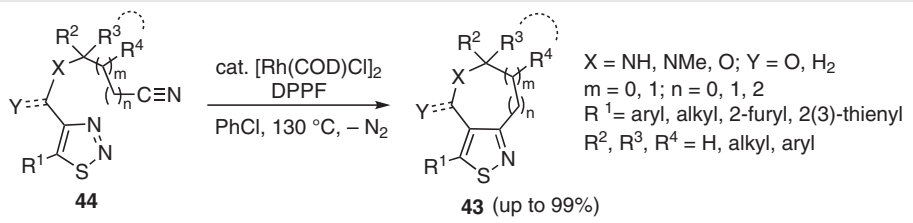

Scheme 21 Intramolecular cyclization of cyanothiadiazoles in the synthesis of annulated isothiazoles 
preferential for the attack of electrophilic agents. It should be noted that position 5 of the isothiazole ring is more active in nucleophilic substitution reactions than position 3. In some cases, interactions with nucleophilic and electrophilic reagents may lead to the ring-opening of the isothiazole. 33

The achievements in the development of methods for the functionalization of the isothiazole nucleus and advances in the transformation of the side chains of the heterocycle, without involving the heterocycle itself in the reaction, will be considered separately. Significant attention will be paid to the development of the chemistry of halogen-substituted isothiazoles, which are highly reactive synthetic blocks, allowing the ability to obtain polyfunctional isothiazoles with a wide variety of substituents.

Fairly recently, the possibility of direct oxidative alkenylation of the isothiazole heterocycle at the unsubstituted position 4 was investigated, and it was found that the reactions proceeded with low yields. This was demonstrated by the example of the reaction of 3-methyl-5-phenylisothiazole (47) with $n$-butyl acrylate (48). ${ }^{67}$ In addition, along with product $49,52 \%$ of the initial isothiazole 47 was recovered from the reaction mixture (Scheme 23).

$$
\text { (15\%) }
$$

Scheme 23 Oxidative alkenylation of the isothiazole ring

It should be noted that the introduction of isoxazole, an isothiazole heteroanalogue, to the reaction under the same conditions led to the formation of the target alkenyl isoxazoles, with yields of $50-68 \%$.

Because of this, the Heck reaction using haloisothiazoles remains the preferred method of alkenylation of the isothiazole heterocycle, despite the moderate yields of the corresponding alkenyl isothiazoles and the formation of a noticeable amount of by-product. ${ }^{68}$ In recent years, considerable attention has been paid to metalation reactions of the isothiazole core for the subsequent preparation of reactive isothiazole blocks for cross-coupling reactions. Advances in this field of isothiazole chemistry have been discussed in detail by Nutaitis. ${ }^{69}$

A mild approach to synthesize 3-amino-substituted isothiazole sulfoxides $\mathbf{5 0}$ through oxidation of the corresponding 3-aminoisothiazoles $\mathbf{5 1}$ with arylsulfonyloxaziridines 52 has been reported (Scheme 24). ${ }^{70}$ Only minor amounts of dioxides $\mathbf{5 3}$ were formed under the described conditions. The reactivity of the resulting isothiazole sulfoxides toward sulfur nucleophiles has been studied and resulted in the formation of 5-sulfanyl-substituted 4,5-dihydroisothiazoles.

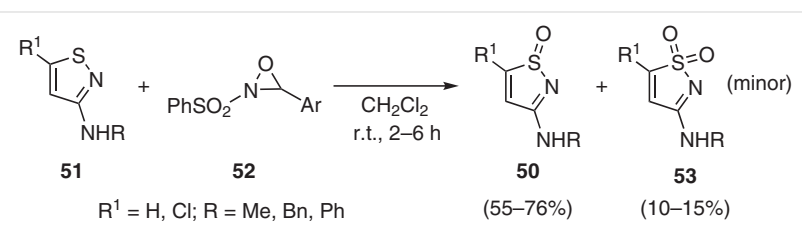

Scheme 24 Oxidation of the sulfur atom in 3-aminoisothiazoles with arylsulfonyloxaziridines

In 2019, the same group developed an advanced approach for the synthesis of chiral 3-amino-substituted isothiazole sulfoxides by utilizing (+)- and (-)-[(8,8-dichlorocamphoryl)sulfonyl]oxaziridine under microwave irradiation. $^{71}$

Relatively little work in the literature is devoted to the transformations of chlorine-substituted isothiazoles; however, these compounds enter into similar reactions to their bromine and iodine analogues, but often under more severe conditions and react at slower rates.

Thus, 3,5-dichloro-4-cyanoisothiazole (54) reacts regiospecifically with phenylboronic acid by substitution of the chlorine at position 5 and gives 5-phenyl-3-chloro-4-cyanoisothiazole (55) in a high yield. In the same way, substitution of the chlorine at position 5 proceeds with the use of potassium phenyltrifluoroborate (Scheme 25). 3,5-Dibromo-4-cyanoisothiazole reacts similarly, but the reaction proceeds at a faster rate. ${ }^{72}$

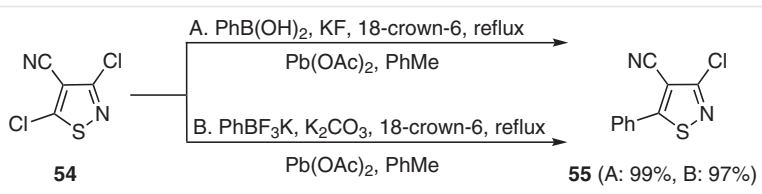

Scheme 25 Selective arylation of 3,5-dichloro-4-cyanoisothiazole

In some cases when using chlorine derivatives of isothiazoles, it is possible to synthesize the target compounds with yields greater than those obtained when using bromo derivatives.

Thus, it was found that 3-bromo(chloro)isothiazole-4carbonitriles $\mathbf{5 6} \mathbf{a}$ and $\mathbf{5 6 b}$ allow direct arylation at position 5 of the heterocycle in the presence of silver fluoride to give the corresponding 5-phenylisothiazoles $\mathbf{5 7 a}$ and 57b (Scheme 26). ${ }^{73}$ Conditions for the preparative synthesis of diisothiazole derivatives 58a and $\mathbf{5 8 b}$ were also developed. Chlorine derivatives of isothiazole were formed in high yields, both in the case of arylation and in the synthesis of diisothiazole derivatives.

Recently it has been shown that with the introduction of pyrrolidine into the nucleophilic substitution reaction of bromine in 3-bromo-4,5-dicyanoisothiazole (59), the main product was 2-[di(pyrrolidin-1-yl)methylene]malononitrile (60), while the expected product, 4,5-dicyano-3-(pyrrolidin-1-yl)isothiazole (61), was either not formed at all or 


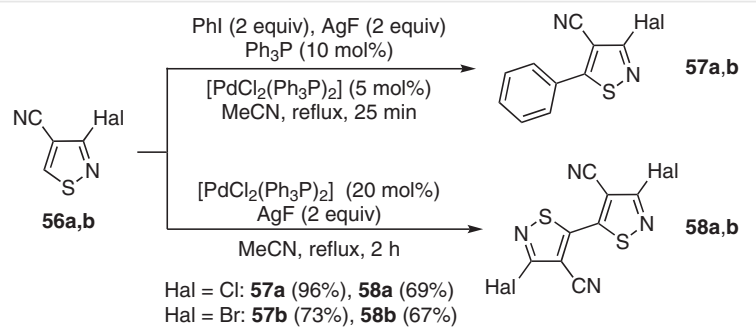

Scheme 26 Aryl-aryl coupling of 3-halogen-substituted isothiazole-4carbonitriles

was only formed in small amounts (Scheme 27). ${ }^{74}$ By varying the temperature and duration of the reaction, the maximum yield of isothiazole $\mathbf{6 1}$ reached $11 \%$.

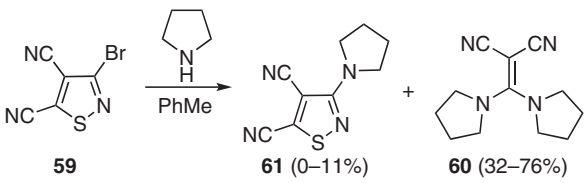

Scheme 27 Nucleophilic substitution in 3-bromo-4,5-dicyanoisothiazole

At the same time, with the introduction of 4,5-dicarbonitrile-3-chloroisothiazole (62) into a similar reaction, a $37 \%$ yield of 4,5-dicarbonitrile-3-(pyrrolidin-1-yl)isothiazole (61) was achieved by varying the temperature and reaction time (Scheme 28).

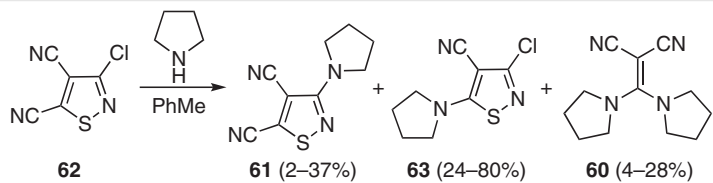

Scheme 28 Nucleophilic substitution in 3-chloro-4,5-dicyanoisothiazole

It is noteworthy that Kalogirou and Koutentis ${ }^{74}$ managed to find conditions under which the reaction of nitrile 62 with pyrrolidine resulted in replacement of the nitrile function at position 5, forming 4-carbonitrile-5-(pyrroli- din-1-yl)-3-chloroisothiazole (63) with an 80\% yield (Scheme 28). Koutentis suggested that the most likely precursor of dinitrile $\mathbf{6 0}$ is 2-(pyrrolidin-1-yl)ethene-1,1,2-tricarbonitrile (64), which was formed from the substituted isothiazoles 59 and 62 when interacting with pyrrolidine via nucleophilic attack on the sulfur. The resulting 2-(pyrrolidin-1-ylthio)ethene-1,1,2-tricarbonitrile $\mathbf{6 5}$ then gives trinitrile $\mathbf{6 4}$ on eliminating the sulfur atom. The subsequent interaction of intermediate $\mathbf{6 4}$ with pyrrolidine leads to the formation of dinitrile $\mathbf{6 0}$ (Scheme 29).

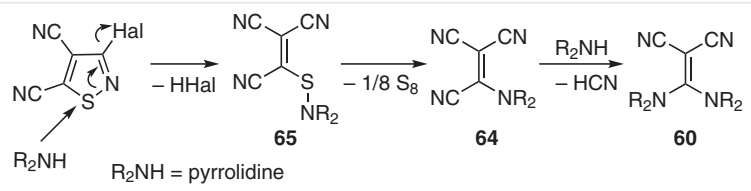

Scheme 29 Elimination of the sulfur atom from 4,5-dicarbonitrile3-halogeno isothiazoles under the action of secondary amines

The chemistry of chlorine-substituted isothiazoles was developed in the Laboratory for Organoelement Compounds of the Institute of Physical Organic Chemistry at the National Academy of Sciences of Belarus. In the course of the research conducted at the laboratory, it was shown that isothiazoles containing chlorine atoms at positions 4 and 5 of the heterocycle and an electron-withdrawing group at position 3, successfully enter into a nucleophilic substitution reaction. When this occurs, the chlorine atom at position 5 of the heterocycle is replaced, while position 4 remains unaffected. Research on the transformation pathways of perchloroisothiazoles was initiated with 4,5dichloro-3-trichloromethylisothiazole, on the basis of which many previously undescribed substituted 4chloroisothiazoles were synthesized.

Thus, the reactions of 4,5-dichloro-3-trichloromethylisothiazole (66) with N,S-nucleophiles were studied, and it was found that the interactions with heterocyclic amines in dimethylformamide resulted in 5-amino-substituted 3-trichloromethyl-4-chloroisothiazoles $\mathbf{6 7 a - d},{ }^{75}$ while reactions with alkyl(aryl)thiolates in ethyl alcohol led to the formation of the corresponding 5-alkyl(aryl)sulfanyl-3-trichloromethyl-4-chloroisothiazoles 68a-c (Scheme 30). ${ }^{76}$

$$
\begin{array}{lll}
\text { (n) } &
\end{array}
$$

Scheme 30 Nucleophilic substitution in 4,5-dichloro-3-trichloromethylisothiazole 

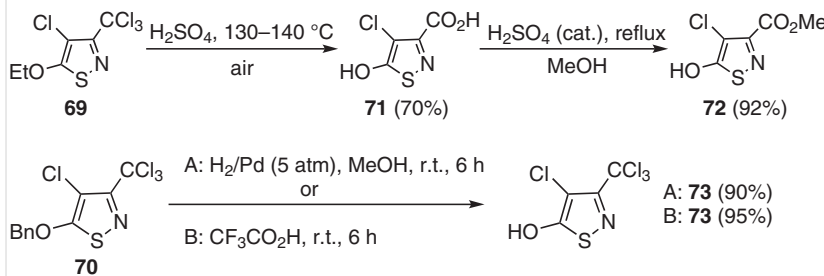

Scheme 31 A new synthetic approach toward 5-hydroxy-4-chloroisothiazoles

Starting from perchloroisothiazole 66, 5-ethoxy-4chloro-3-trichloromethylisothiazole (69) and 5-benzyloxy4-chloro-3-trichloromethylisothiazole (70) were synthesized by reactions with sodium ethylate and benzylate in tetrahydrofuran, and were used in the development of new synthetic methods toward 5-hydroxy-4-chloroisothiazoles (Scheme 31). ${ }^{77}$ Thus, treatment of the 5-ethoxy derivative 69 with hot sulfuric acid allowed 5-hydroxy-4-chloroisothiazolecarboxylic acid (71) to be obtained in a good yield, which was then esterified under acidic conditions to form the methyl ester 72. 5-Benzyloxyisothiazole $\mathbf{7 0}$ was transformed into 5-hydroxy-4-chloro-3-trichloromethylisothiazole (73) in preparative yields by the action of hydrogen in the presence of palladium on carbon (A) or by treatment with trifluoroacetic acid (B).

The reactions of 4,5-dichloroisothiazole-3-carboxylic acid (74), synthesized from 4,5-dichloro-3-trichloromethylisothiazole $(\mathbf{6 6}),{ }^{32}$ with $\mathrm{S}, \mathrm{N}$-nucleophiles have been studied. Reactions with thiols were carried out in diethyl ether in the presence of pyridine, which resulted in 5-alkyl(phenyl)sulfanyl-4-chloroisothiazole-3-carboxylic acids 75a-c in yields of $52-65 \%$ (Scheme 32$){ }^{76}$

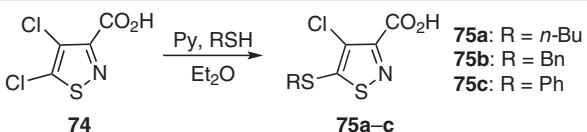

Scheme 32 Nucleophilic substitution in 4,5-dichloroisothiazole-3carboxylic acid

Subsequently, 4,5-dichloroisothiazole-3-carboxylic acid tert-butyl ester 76, obtained from acid chloride 77, was used to study the possibility of carrying out reactions with $\mathrm{N}$-nucleophiles (Scheme 33). The possibility of promoting the nucleophilic substitution of the chlorine atom at the 5position of the heterocycle with amines in the presence of fluorine ions was demonstrated. ${ }^{78}$ The yield of the corresponding 5-aminoisothiazoles $\mathbf{7 8}$ varied depending on the solvent selected, on the presence of fluoride ions in the reaction mixture, on the temperature, and on the nature of the amine added to the reaction.

The reactivity of amines in the nucleophilic substitution of the chlorine atom at position 5 decreases in the series shown in Figure 1.

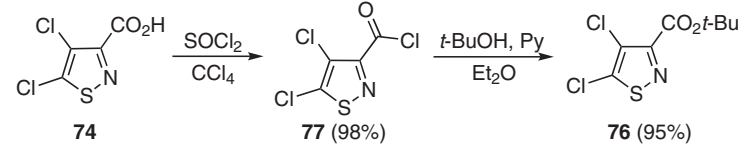

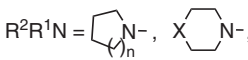

$\mathrm{RHN}-, \mathrm{RMeN}-, \mathrm{R}_{2} \mathrm{~N}-$

$(\mathrm{R}=$ alkyl; $\mathrm{n}=1,2 ; \mathrm{X}=\mathrm{NH}, \mathrm{O})$

Scheme 33 Nucleophilic substitution in tert-butyl ester of 4,5-dichloroisothiazole-3-carboxylic acid

Other derivatives such as 4,5-dichloroisothiazole-3-carboxylic acids $\mathbf{7 9},{ }^{79}$ metallocenic ${ }^{80}$ and macrocyclic examples, ${ }^{81}$ as well as various amides $\mathbf{8 0}$ were also obtained starting from acid chloride $\mathbf{7 7}$ (Scheme 34 ).

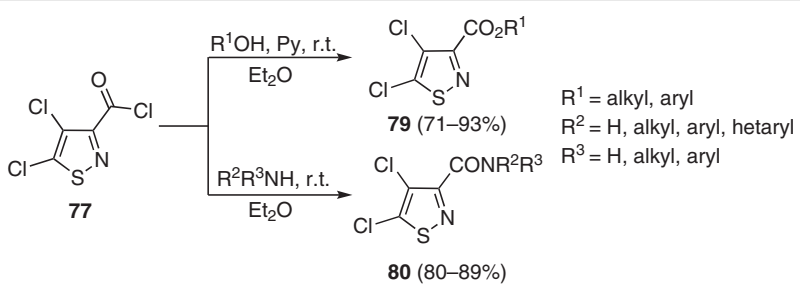

Scheme 34 Synthesis of amides and esters of 4,5-dichloroisothiazole3-carboxylic acid

Aryl ketones 81a-c were synthesized through the Friedel-Crafts acylation reaction using acid chloride $\mathbf{7 7}$ (Scheme 35). ${ }^{82}$ (4,5-Dichloroisothiazol-3-yl)ferrocenylketone was also prepared in a similar manner. ${ }^{83}$

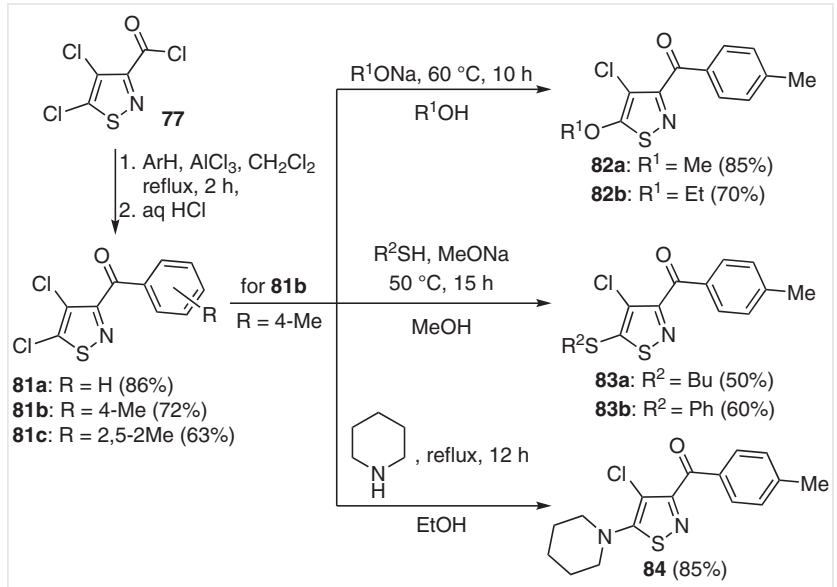

Scheme 35 Preparation of 3-ketoderevatives of 4,5-dichloroisothiazole

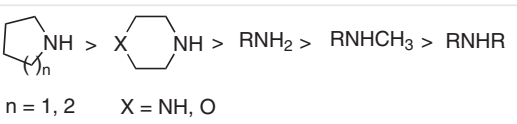

Figure 1 
Reactions with O-, N- and S-nucleophiles were investigated using ketone $\mathbf{8 1 b}$. The reactions of this ketone with O-nucleophiles - sodium alkoxides - in a medium of the corresponding alcohol at $60{ }^{\circ} \mathrm{C}$ resulted in alkoxy derivatives 82a and 82b, while reactions with S-nucleophiles sodium thiolates, generated in situ in anhydrous methanol, led to the corresponding sulfides $\mathbf{8 3} \mathbf{a}$ and $\mathbf{8 3 b}$. The reaction with piperidine, as an example of an N-nucleophile, was carried out in ethanol with a double excess of piperidine, and the yield of the corresponding 5-piperidinyl derivative $\mathbf{8 4}$ was $85 \%$ (Scheme 35 ).

Some of the synthesized isothiazole-containing amides, esters, and ketones were able to exhibit potentiating activity in compositions with the insecticides imidacloprid and/or $\alpha$-cypermethrin, with larvae of the Colorado potato beetle. ${ }^{84-87}$ Some derivatives with fungicidal activity were also found. ${ }^{88}$ In the case of $\alpha$-cypermethrin, when used in a composition with an insecticide, the maximum synergistic effect was achieved by using a 4,5-dichloroisothiazole derivative with $5-10 \%$ of the active component of the insecticidal composition. ${ }^{89}$

Based on 4,5-dichloroisothiazole-3-carboxylic acid amide (85) and azide 86, both obtained from 4,5-dichloroisothiazole-3-carboxylic acid chloride (77), 3-amino-4,5-dichloroisothiazole (87) was synthesized by the Hoffmann and Curtius reactions..$^{90}$ It was possible to achieve a $92 \%$ amine yield via the preliminary in situ preparation of ethyl carbamate 88, which was then subjected to alkaline hydrolysis (Scheme 36).

4,5-Dichloroisothiazole-3-carboxylic acid nitrile (89) was synthesized by the action of phosphorus pentoxide on 4,5-dichloroisothiazole-3-carboxylic acid amide (85), both without solvent and in tetrachlorethylene. In both cases, the target nitrile was obtained in a quantitative yield. ${ }^{91}$ Subsequently, reactions of the synthesized nitrile with $\mathrm{O}-, \mathrm{N}-$ and S-nucleophiles were studied (Scheme 37).

The reaction with O-nucleophilic sodium methoxide led to the formation of a mixture of 5-methoxy-4-chloro-3-cyanoisothiazole (90a) and the product of its alcoholysis $\mathbf{9 0 b}$,

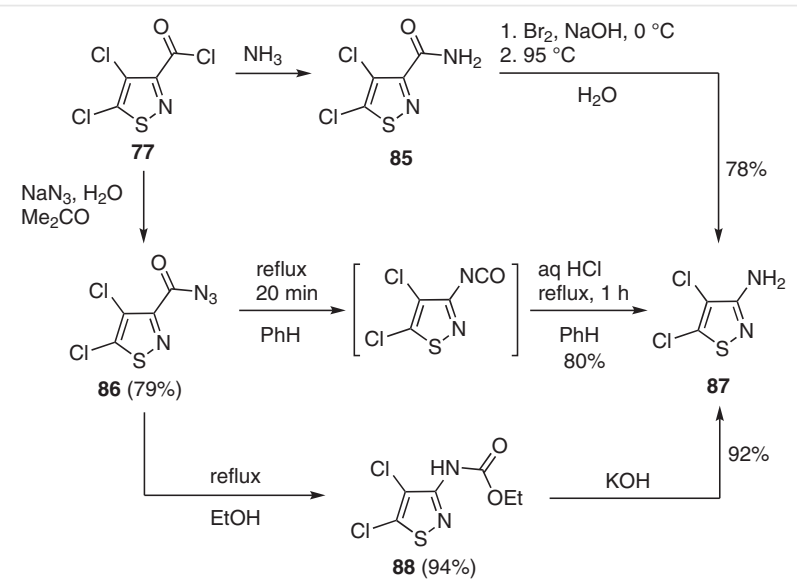

Scheme 36 Pathways to the synthesis of 3-amino-4,5-dichloroisothiazole

whilst the reaction with piperidine in methanol led to the formation of 5-piperidinyl-substituted isothiazole 91. Reactions with thiolates using benzylmercaptan and thiophenol as thiols proceeded in methanol with satisfactory yields, with the formation of derivatives 92a and $\mathbf{9 2 b}$, respectively. When $n$-butylmercaptan was used, a mixture of the thiobutyl derivative 93a and the product of its alcoholysis $\mathbf{9 3 b}$ was formed. In isopropyl alcohol, the yield of isothiazole 93a was $68 \%$.

The possibility of further transformation of the nitrile group was illustrated by synthesizing disubstituted 1,2,4oxadiazoles 94 after obtaining the 4,5-dichloroisothiazole3-carboxylic acid amidoxime 95, and its subsequent acylation and cyclization (Scheme 38). ${ }^{92}$

The yields of acylamidoximes 96 were $85-95 \%$ for all derivatives, except for the case when the acylation was carried out with trichlorovinylacetic acid, for which the yield of the corresponding acylamidoxime was $71 \%$. Method B provided slightly higher yields of the target acylamidoximes compared with method A. The acylamidoximes were further cyclized in the presence of acetic acid at reflux in yields of

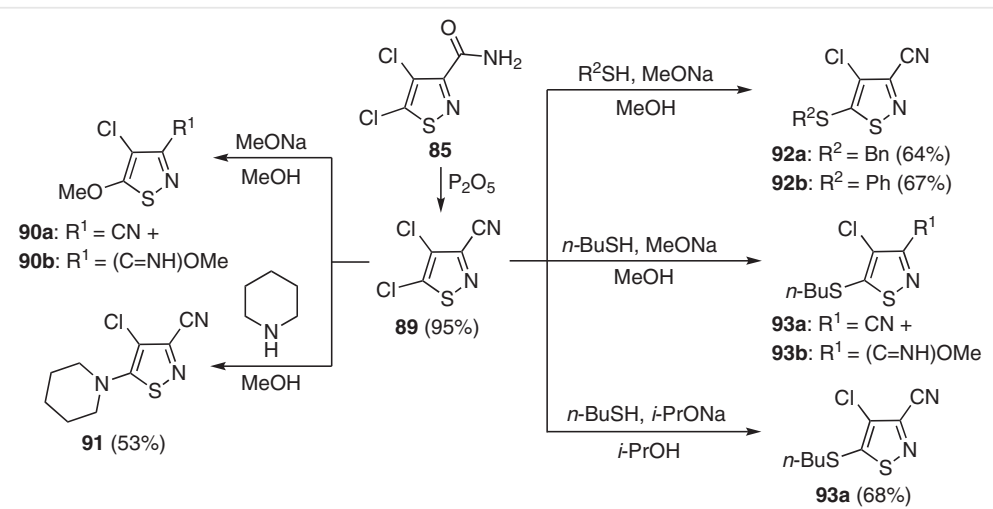

Scheme 37 Synthesis and modifications of 4,5-dichloroisothiazole-3-carboxylic acid nitrile 


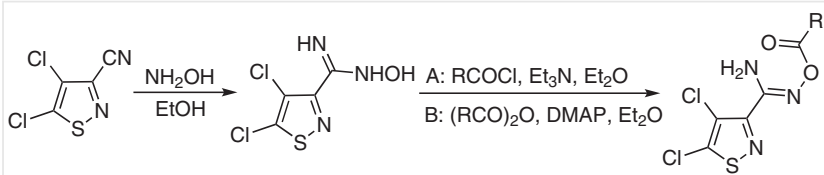

$$
\begin{aligned}
& 89 \quad 95 \\
& \mathrm{R}=\mathrm{Me}, i-\mathrm{Pr}, \mathrm{Ph}, \mathrm{CH}_{2}-\mathrm{CCl}=\mathrm{CCl} \\
& \text { 4,5-dichlorothiazol-3-yl } \\
& 96(71-95 \%)
\end{aligned}
$$

Scheme 38 Transformation of the nitrile group in 3-cyano-4,5-dichloroisothiazole to 1,2,4-oxadiazole ring

90-92\% (Scheme 38). In the case of pivaloylamidoxime, the heterocyclization did not proceed under the proposed conditions, presumably due to steric hindrance.

Nitrile $\mathbf{8 9}$ was successfully used as a starting material for the synthesis of isothiazole-containing alkyl ketones 97a and 97b by addition reactions with alkylmagnesium halides (Scheme 39). ${ }^{93}$

$$
\begin{aligned}
97 \mathrm{a}: \mathrm{X}=\mathrm{Br}, \mathrm{R}=\mathrm{Et}(70 \%) \\
97 \mathrm{~b}: \mathrm{X}=\mathrm{I}, \mathrm{R}=\mathrm{Me}(80 \%)
\end{aligned}
$$

Scheme 39 Preparation of 3-alkylketo-4,5-dichloroisothiazoles

The possibility of using alkyl (4,5-dichloroisothiazol-3yl)ketones for the synthesis of functionally substituted isothiazoles through replacement of the chlorine at position 5 of the heterocycle and the transformation of alkylcarbonyl fragment was evaluated with (4,5-dichloroisothiazol-3-yl) methyl ketone (97b) as an example (Scheme 40). ${ }^{93}$

$$
\text { i-PrOH }
$$

Scheme 40 Some transformations of 3-acetyl-4,5-dichloroisothiazole

First, reactions with amines were investigated. It had been previously shown that the reaction of (4,5-dichloroisothiazol-3-yl) phenyl ketone with amines proceeded with substitution of the chlorine atom at position 5 of the heterocycle by the amine residue. In aprotic bipolar solvents ( $\mathrm{N}$-methylpyrrolidone and DMSO) at $130-140{ }^{\circ} \mathrm{C}$, the process was complete in 6 hours. ${ }^{94}$ Compared to (4,5-dichloroisothiazol-3-yl)(4-methylphenyl) ketone, the reactions of ketone 97b with amines (morpholine and piperi- dine) were more active. In a DMSO solution at $70^{\circ} \mathrm{C}$, nucleophilic substitution of the chlorine atom at position 5 of the heterocycle was complete within 5 hours, with good yields being obtained. The ketones $\mathbf{9 7 \mathbf { b }}$ and $\mathbf{9 8} \mathbf{a}$ were further reduced to secondary alcohols $99 \mathbf{a}$ and $\mathbf{9 9 b}$ by the action of sodium borohydride in isopropanol (Scheme 40).

In addition, the reactions of (4,5-dichloroisothiazol-3yl) methyl ketone (97b) with elemental bromine in carbon tetrachloride and anhydrous acetic acid were studied (Scheme 41). Bromination in these two solvents proceeded with significant tar formation, leading to bromomethyl(4,5dichloroisothiazol-3-yl) ketone $\mathbf{1 0 0}$ in yields of $32 \%$ and $46 \%$, respectively. Substitution of two hydrogen atoms in the methyl group for bromine atoms was not observed. The reaction in carbon tetrachloride was complete in 2 hours, whilst the bromination in acetic acid was complete in 1 hour. It was noted that replacement of the solvent with chloroform or dichloromethane did not lead to positive results; in both cases, the bromination did not proceed. The reaction of bromoketone $\mathbf{1 0 0}$ with thiourea in an ethanol solution at $60{ }^{\circ} \mathrm{C}$ proceeded smoothly over 3 hours and resulted in 2-amino-4-(4,5-dichloroisothiazol-3-yl)thiazole (101) in a yield of $82 \%$.

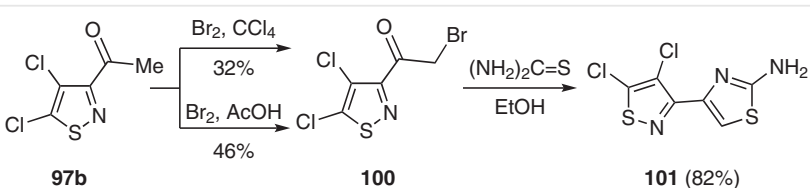

Scheme 41 Modification of the acyl substituent in (4,5-dichloroisothiazol-3-yl) methyl ketone

The synthesis of novel isothiazolyl-cymantrene derivatives of $1 H$-pyrazole-1-carboxamide 102, dihydroisoxazole 103 and $1 H$-pyrazole-1-carbothioamide 104 was reported on the basis of the transformation of cymantrenyl chalcone 105, obtained through condensation of aldehyde 106 and acetylcymantrene (Scheme 42). ${ }^{95}$
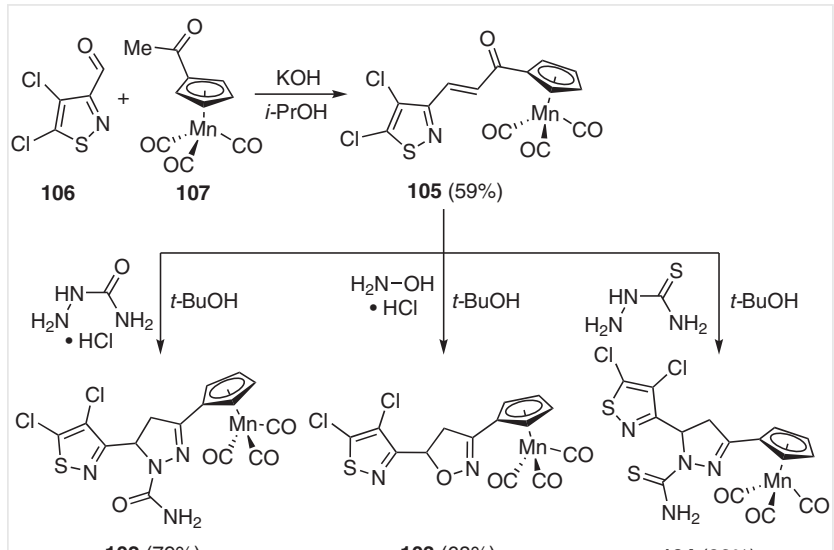

$$
102(79 \%)
$$

$103(68 \%)$

Scheme 42 Synthesis and transformations of cymantrenyl substituted isothiazoles 


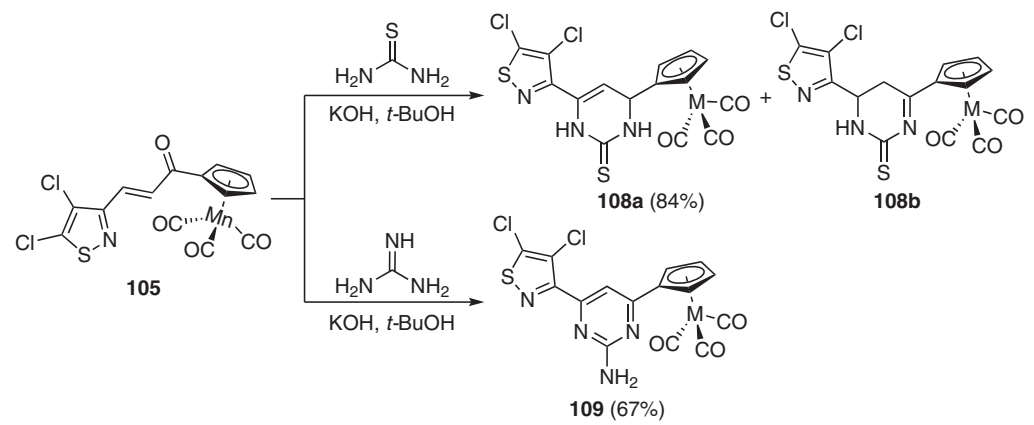

Scheme 43 Construction of polynuclear derivatives of isothiazole

The reaction of chalcone 105 with thiourea allowed 3,4dihydro- and 5,6-dihydropyrimidine- $2(1 H)$ thiones 108a and 108b to be obtained in an overall yield of $84 \%$, and the reaction with guanidine hydrochloride afforded 2-aminopyrimidine derivative $\mathbf{1 0 9}$ (Scheme 43 ).

Reaction of aldehyde 106 with 1,1'-diacetylferrocene (110) allowed 3-(4,5-dichloroisothiazol-3-yl)[5]ferrocenophane-1,5-dione 111 to be obtained (Scheme 44). ${ }^{83}$

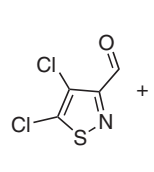

106
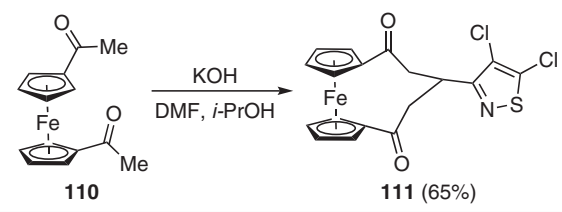

Scheme 44 Design of ferrocenyl containing isothiazoles

The conversion of various isothiazoles 112 into pyrazoles on treatment with hydrazine was investigated. The influence of various C-3, C-4 and C-5 isothiazole substituents and some limitations of this ring transformation were examined in detail. ${ }^{96}$ It was found, that when the isothiazole C-3 substituent was a good nucleofuge, 3-aminopyrazoles 113 were obtained. However, when the 3-substituent was not a leaving group it was retained in the pyrazole product 114 (Scheme 45).

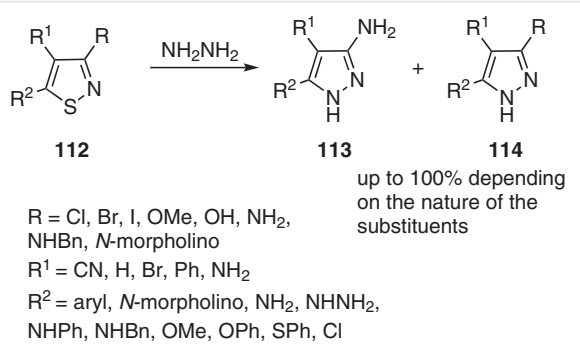

Scheme 45 Conversion of isothiazoles into aminopyrazoles

\section{Selected Synthesis of Biologically Active Isothiazole Derivatives}

As already mentioned, compounds containing an isothiazole fragment have a broad spectrum of biological activity, including pesticidal, anticancer, antimicrobial, and antiviral. The mechanism of the biological action of these compounds has only been studied for some of their representatives.

For example, compound 115 (Figure 2 ) is a vascular endothelium growth factor receptor inhibitor (VEGFR-2) of tyrosine kinase, and it has been proposed as an anticancer therapy drug that prevents the growth and metastasis of tumors. ${ }^{97}$ Although being an inhibitor of a protein significant for the treatment of cancer diseases, a reinforcing effect was not observed during clinical trials in combination with known antitumor drugs. ${ }^{98}$ Isothiazole-modified nucleoside $\mathbf{1 1 6}$ (Figure 2) is effective against the first type of herpes virus (HSV-1), and the interaction mechanism involves its binding to thymidine kinase HSV- $1 .{ }^{99}$

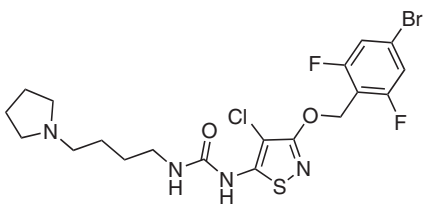

115

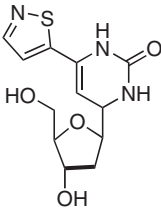

116
Figure 2 Examples of biologically active isothiazoles for which the mechanism of biological activity has been proposed

Recently, it has been shown that the isothiazole nuclei of a number of derivatives can interact with target biomolecules, not only through van der Waals interactions and hydrogen bonds, ${ }^{100,101}$ but also by covalent binding at the unsubstituted position 4 of the heterocycle as a result of bioactivation. ${ }^{102}$ This is an important factor that must be considered when designing and synthesizing new biologically active compounds containing an isothiazole heterocycle. 
The available literature data on the synthesis of biologically active isothiazoles includes not only information about the relationships between the structures of compounds and their biological activities, but also important information on the approaches used in multistep targeted syntheses of isothiazole-containing molecules. Considering the target functionalization of isothiazoles, it seems appropriate to pay attention not only to individual methods of isothiazole heterocycle formation and ways of modification, but also to synthetic strategies and approaches used in multistage syntheses of target isothiazoles. As examples of such strategies and approaches, the synthetic schemes toward some biologically active isothiazoles appear particularly useful and informative. At the same time, attention will be paid to the stages that include the formation or involvement of the isothiazole heterocycle in chemical transformations.

We can identify three rather conventional strategies for the targeted production of biologically active isothiazoles:

(1) Introduction of the isothiazole fragment at the final stage.

(2) Convergent synthesis of functionalized isothiazoles.

(3) Multistage synthesis based on the isothiazole nucleus.

As an example of the first strategy, we can cite the final stages of the synthesis of nucleoside $\mathbf{1 1 6}$ (Scheme 46). ${ }^{99}$ 3',5'-Di-O-acetyl-2-deoxy-5-iodouridine $\mathbf{1 1 7}$ was introduced into the Sonogashira reaction with 3,3-diethoxyprop-1-yne (118) and subsequent hydrolysis of the obtained alkyne derivative $\mathbf{1 1 9}$ gave aldehyde 120. This in turn was reacted with sodium thiosulfate and the resulting thiosulfate derivative $\mathbf{1 2 1}$ was treated with liquid ammonia without purification to give nucleoside $\mathbf{1 1 6}$.
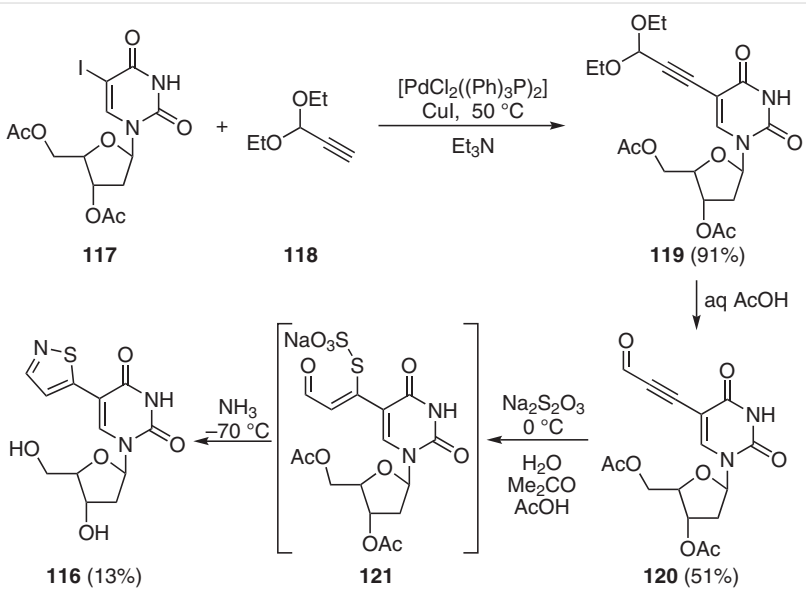

Scheme 46 Synthesis of a nucleoside bearing an isothiazole ring

In this example, the formation of the isothiazole ring is a factor limiting the yield of the target nucleoside 116. However, low yields of the target products can be justified during initial research and bio-testing, and if necessary (for example, when the desired biological activity is detected), further optimization of the procedure can be carried out.

Another example of this strategy is the formation of substituted isothiazoles via the transformation of other functionalized heterocycles such as isoxazoles. Thus, in the synthesis of cyclooxygenase inhibitor 1 (COX-1) analogues, isothiazole derivative $\mathbf{1 2 2}$ was obtained starting from isoxazole inhibitor 123 through reductive opening of the isoxazole ring with hydrogen in the presence of Raney nickel, followed by cyclization of the resulting enamine ketone $\mathbf{1 2 4}$ by the action of phosphorus pentasulfide in the presence of chloranil (Scheme 47). ${ }^{103}$

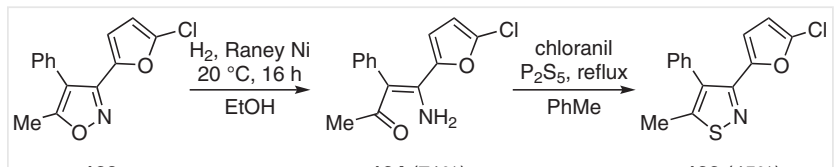

123

$124(71 \%)$

$122(45 \%)$

Scheme 47 Synthesis of cyclooxygenase inhibitor 1 (COX-1) analogues with the fragment of isothiazole

This method has several disadvantages; however, the yield of the corresponding enamine ketones (38-90\%) strongly depends on the substituents present on the isoxazole ring, and their cyclization into isothiazoles usually proceeds with rather low yields (21-51\%). ${ }^{104}$ Regardless, this pathway can be useful in the synthesis of promising biologically active compound libraries for biological screening, subject to the availability of the corresponding substitute isoxazoles.

The strategy associated with the convergent synthesis of isothiazoles, including demonstrating the potential of isothiazole halogen derivatives in preparative organic synthesis, was used in the final stage of the preparation of a selective inhibitor of the metabotropic glutamate receptor 5 (mGluR5) 125 (Scheme 48). ${ }^{105,106}$ 3,4-Dibromisothiazole amide 126 was introduced into a Suzuki cross-coupling reaction with boric acid pinacol ester 127. The product 128 thus obtained was then subjected to a Stille reaction with the pyridine organotin derivative $\mathbf{1 2 9}$ to deliver the target product 125.

Perhaps the most common strategy is sequential multistep synthesis based on the isothiazole core with reactive substituents. This method is used in the synthesis of a number of substituted 2-(isothiazol-3-yl)-1,3,4-oxadiazoles 130 possessing significant antimitogenic activity, achieved through the depolymerization of microtubules (Scheme 49). ${ }^{107}$

Hydrazide 131, obtained from 4-aminoisothiazole-3carboxylic acid amide (132), was further reacted with aryl isothiocyanates. The substituted acylsemicarbazides thus synthesized were transformed by the action of $N, N^{\prime}$-dicyclohexylcarbodiimide (DCC) into 1,2,4-oxadiazoles 133, which were subjected to reductive amino group alkylation. 


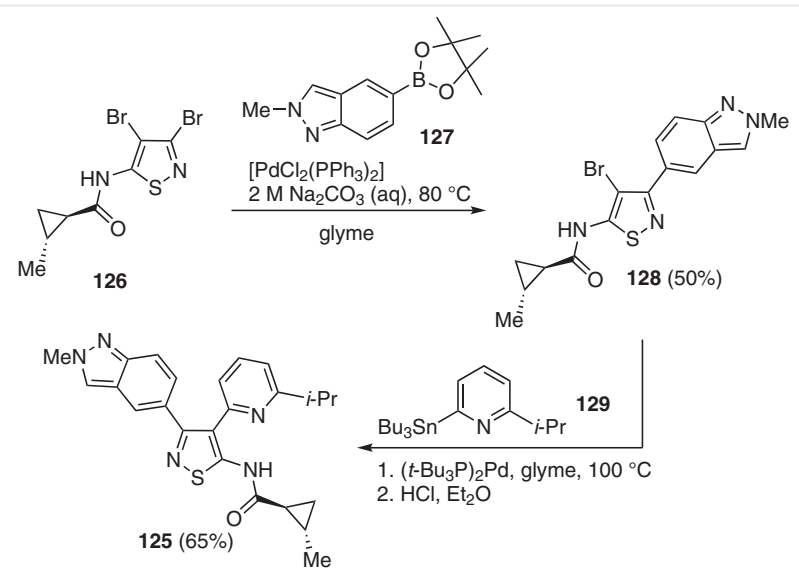

Scheme 48 A selective inhibitor of the metabotropic glutamate receptor 5 (mGluR5) with the isothiazole central nucleus

An alternative method for the synthesis of the desired isothiazol-3-yl-oxadiazoles consisted of the initial reductive alkylation of compound 132, transformation of the amide groups of the resulting compounds $\mathbf{1 3 4}$ into hydrazide groups, subsequent formation of semicarbazides, and then formation of the 1,3,4-oxadiazole fragments.

A series of vanillin-containing isothiazole derivatives was synthesized by successive transformations of the substituents on the isothiazole nucleus. It has previously been shown that 4,5-dichloroisothiazole-3-carboxylic acid vanillin ester exhibits potentiating activity in a composition with the pyrethroid insecticide cypermethrin, and its azomethine and amine derivatives possess potentiating activity when combined with the neonicotinoid insecticide imidacloprid. ${ }^{85,108}$ The effect was observed when testing the corresponding insecticidal compositions on Colorado potato beetle larvae. In order to clarify the effect of structural and functional changes in the molecules of the vanillin isothiazole derivatives on their biological activity, an isovanillin analogue of the isothiazole vanillinate was synthesized, as well as 5-alkyl(aryl)thio-substituted 4-chloroisothiazoles containing the vanillin moiety (Scheme 50). ${ }^{109}$ An optimized method was used for producing 5-butyl(benzyl, phenyl)thio-4-chloroisothiazole-3-carboxylic acids 75a-c. The methyl ester of 4,5-dichloroisothiazole-3-carboxylic acid 135 was treated in situ with the corresponding sodium thiolates in anhydrous methanol, followed by hydrolysis of the intermediate methyl-5-alkyl(benzyl, phenyl)thio-4chloroisothiazole-3-carboxylates 136. The synthesis of vanillin esters 137a-c was carried out by the acylation of vanillin with 5-butyl (benzyl, phenyl)thio-4-chloroisothiazole3-carbonyl chlorides 138a-c, which were obtained by boiling the acids $\mathbf{7 5 a} \mathbf{a}-\mathbf{c}$ with thionyl chloride in the presence of a catalytic amount of DMF.

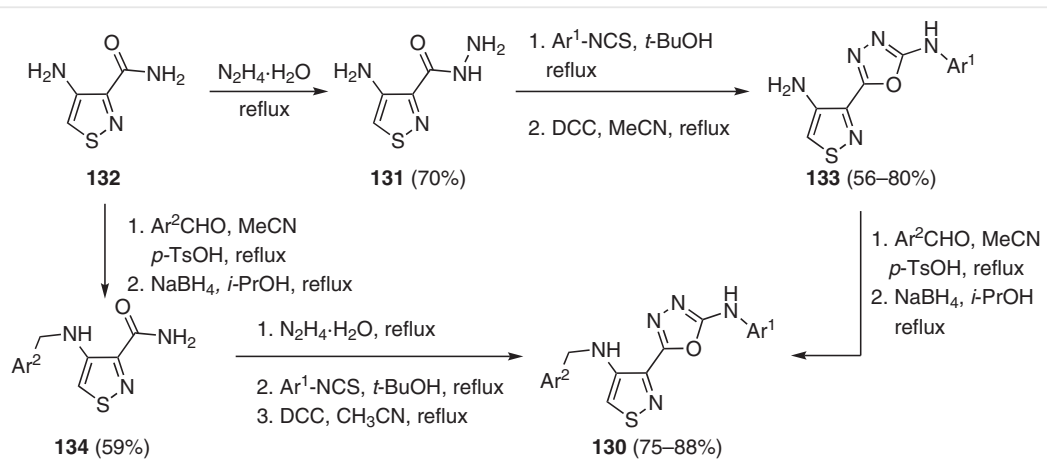

Scheme 49 Synthesis of isothiazol-3-yl-oxadiazoles possessing antimitogenic activity

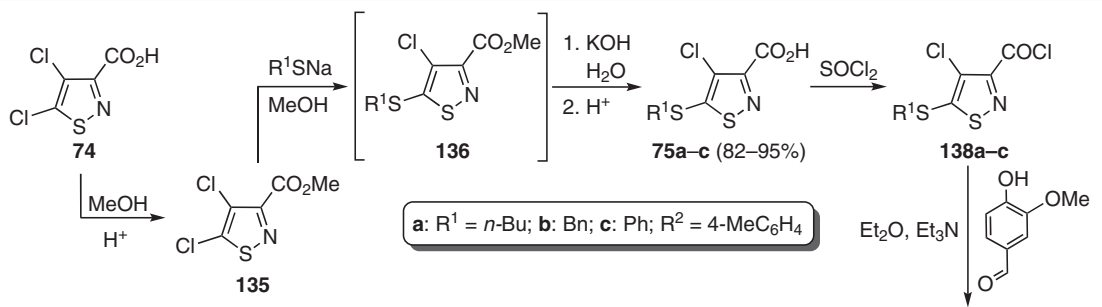

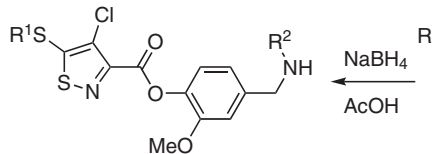

$140 \mathrm{a}-\mathrm{c}(85-93 \%)$

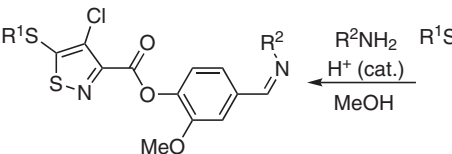

$139 a-c(78-92 \%)$

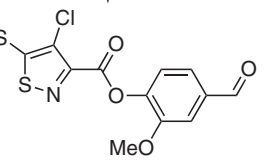

$137 a-c(85-92 \%)$

Scheme $\mathbf{5 0}$ Synthesis of isothiazolic esters of vanillin and their azomethines 
Azomethines 139a-c were obtained by condensation of esters 137a-c with $p$-toluidine in dry methanol, with yields of $78-92 \%$. Compounds 139a-c were further reduced to the corresponding amines 140a-c with high yields by the action of sodium borohydride and acetic acid in benzene.

Vanillin ether 141, containing a 4,5-dichloroisothiazole moiety, and also azomethine 142 based on it, were prepared in order to study the effect of the nature of the linker between the isothiazole and vanillin fragments on the biological activity of vanillin derivatives of isothiazole (Scheme 51). ${ }^{110}$ (4,5-Dichloroisothiazol-3-yl) carbinol 143 was reacted with thionyl chloride in carbon tetrachloride to form (4,5-dichloroisothiazol-3-yl) chloromethane 144 in a satisfactory yield. Alkylation of vanillin with chloromethane 144 in dimethylformamide using sodium hydride as the base led to the formation of vanillin ether $\mathbf{1 4 1}$ in a 71\% yield. The resulting ether was introduced into a condensation reaction with $p$-toluidine in methanol in the presence of a catalytic amount of acetic acid to form azomethine 142 (Scheme 51). Isothiazolic derivatives of comenic acid were prepared in a similar manner. ${ }^{111}$

Another example of such a strategy is the synthesis of the Aurora kinase inhibitor, serine/threonine kinase, which plays a crucial role in cell proliferation (Scheme 52). ${ }^{112}$ Methyl ether 145 was reacted with intermediate 146 in the presence of sodium hydride, and the carboxyl group in the obtained product 147 was reduced by lithium triethylborohydride in tetrahydrofuran. The resulting alcohol 148 was then mesitylated to form ester 149. Transformation of the ester group into a tertiary amino group by reaction with 2(ethylamino)-2-methylpropan-1-ol led to the formation of

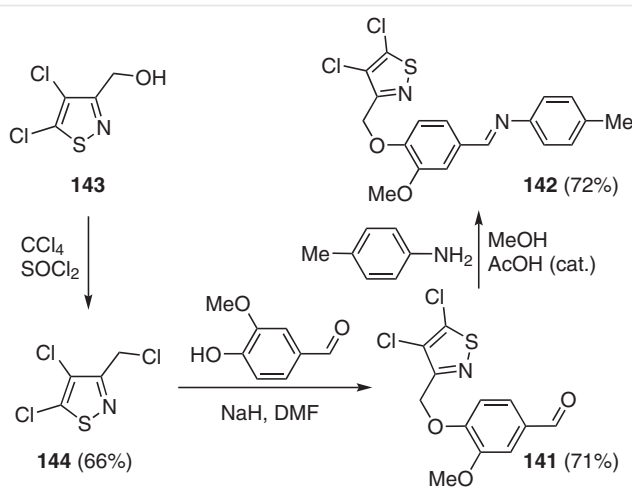

Scheme $\mathbf{5 1}$ Synthesis of isothiazolic ether of vanillin and its azomethine

compound 150. After deprotection of the pyrazole nitrogen by the action of hydrochloric acid in dioxane, the desired inhibitor 151 was obtained.

Finally, using this strategy, a collection of 4-chloroisothiazole-containing carbamides ${ }^{113,114}$ and amides, ${ }^{115}$ as vascular endothelium growth factor receptor inhibitor (VEGFR2) 115 analogues (see Figure 2), was synthesized for biotesting in compositions with known antitumor drugs. Some of the obtained compounds were able to potentiate activity of the known anticancer drugs cisplatin, cytarabine, and etoposide in vitro. ${ }^{113}$

The approach chosen for the synthesis of isothiazolecontaining carbamides included the initial preparation of the corresponding (isothiazol-3-yl)carbonyl azides $\mathbf{8 6}$ and 152. To obtain 5-benzylthio-4-chloroisothiazole-3-carbonyl azide (152), two approaches were tested: using acid chloride $\mathbf{1 3 8 b}$ and 5-benzylthio-4-chloroisothiazole-3-carbox-<smiles>COS(=O)(=O)c1nc(C)cn2c(-c3cnn(S(C)(=O)=O)c3)cnc12</smiles>

145<smiles>[R15]c1cn2c(-c3cnn([Y15])c3)cnc2c(Nc2cc(CO)ns2)n1</smiles>

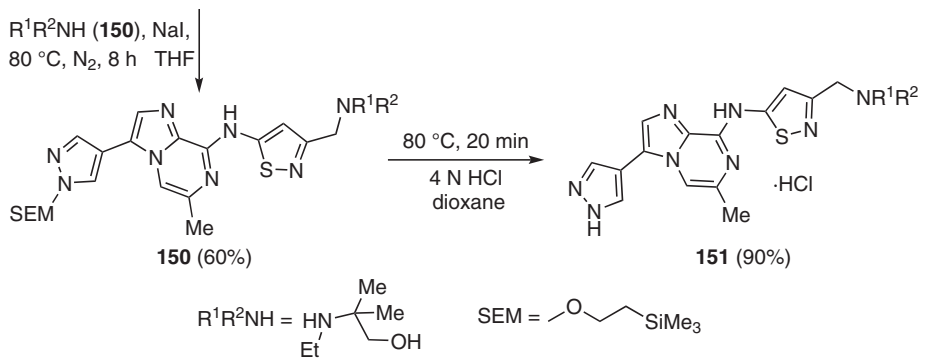

Scheme 52 Synthesis of Aurora kinase inhibitor 


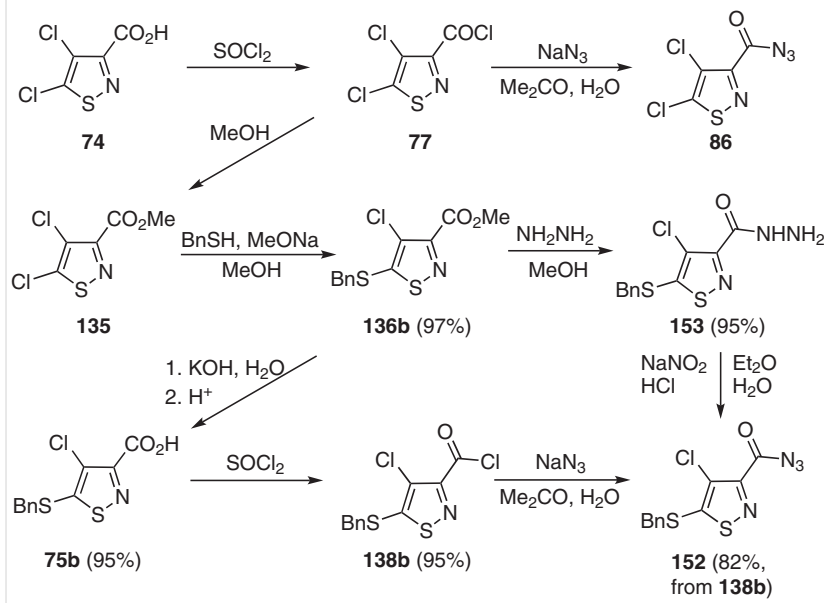

Scheme 53 Approaches to the synthesis of 4-chloroisothiazolecontaining azides

ylic acid hydrazide (153). Treatment of hydrazide $\mathbf{1 5 3}$ with nitrous acid (a mixture of $\mathrm{NaNO}_{2}$ and $\mathrm{HCl}$ ) resulted in the target 5-benzylthio-4-chloroisothiazole-3-carboxylic acid azide (152). However, due to the low solubility of hydrazide 153 under the reaction conditions, the process proceeded slowly and the yield of azide $\mathbf{1 5 3}$ did not exceed 65\%, whereas the reaction of 5-benzylthio-4-chloroisothiazolecarbonyl chloride (138b) and $\mathrm{NaN}_{3}$ gave the target azide 152 in a yield of $82 \%$ (Scheme 53 ).

The hydrazide 153 was synthesized in a $95 \%$ yield by the action of hydrazine hydrate on ester 136b in methanol. Subsequently, azides $\mathbf{8 6}$ and $\mathbf{1 5 2}$ were used to synthesize carbamates, as immediate precursors of ureas (Scheme 54).

The synthesized isothiazolylcarbamates 154a and 154b were further reacted with aliphatic amines, including functionalized examples ( $n$-hexylamine, 6-aminohexanol, 2aminoethoxyethanol, $N^{\prime}, N^{\prime}$-dimethylpropan-1,3-diamine). In addition to the $p$-fluorophenol carbamate, ethyl carbamate 155 was obtained from azide 152; it had greater solubility but did not react with amines under the utilized conditions, even with prolonged boiling of the reaction mixture. In the case of $\gamma$-aminobutyric and $\varepsilon$-aminocaproic acids, which are poorly soluble in chloroform, the reactions with urethanes 154a and 154b were carried out in aqueous ethanol. ${ }^{115}$ The obtained carbamides $\mathbf{1 5 6}$ were then transformed into the corresponding salt forms $\mathbf{1 5 7}$ by treatment with sodium carbonate (Scheme 55).

The amide synthesis involved the acylation of selected amino acids with 4,5-dichloroisothiazole-3-carboxylic acid azide 86 in methanol, followed by conversion of the synthesized amides 158 into their salt forms $\mathbf{1 5 9}$ by reaction with sodium bicarbonate (Scheme 56 ).

Among biologically active isothiazoles, benz[d]isothiazoles occupy an important place. The benz $[d]$ isothiazole moiety has been successfully used in the design and synthesis of neuroleptic ziprasidone as well as in the synthesis of a number of ureas and thioureas, which showed both in vitro antiglycosylation activity and the ability to inhibit urease. ${ }^{116}$ Some ureas and thioureas containing benzo[d]isothiazole fragments show high inhibitory activity against Mycobacterium tuberculosis GyrB DNA gyrase. ${ }^{117}$ In this regard, it is necessary to mention the recently proposed original approach to the synthesis of substituted benz $[d]$ isothiazoles based on the Diels-Alder reaction, which has been successfully demonstrated with the example of 3-phenyl-4,5-bis(carbomethoxy)isothiazole (160) as the starting compound (Scheme 57). ${ }^{118}$

The carboxyl groups of isothiazole $\mathbf{1 6 0}$ were transformed into carbinols by the action of borohydride in an ethanol/tetrahydrofuran medium, forming the diol $\mathbf{1 6 1}$. The carbinol groups of diol $\mathbf{1 6 1}$ were further converted into bromomethyls by reaction with phosphorus tribromide and pyridine in dichloromethane. The reaction of the

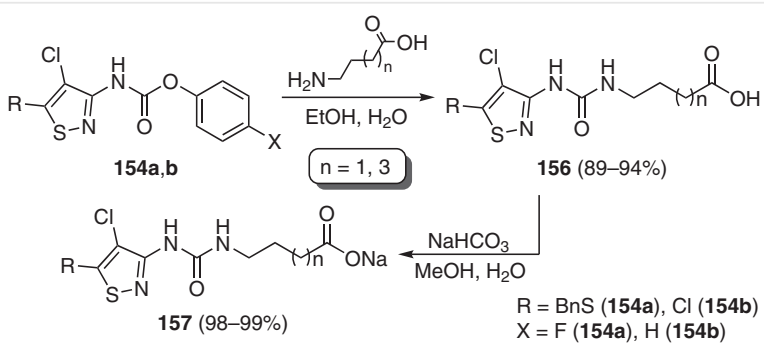

Scheme 55 Preparation of isothiazolic ureas on the basis $\gamma$-aminobutyric and $\varepsilon$-aminocaproic acids

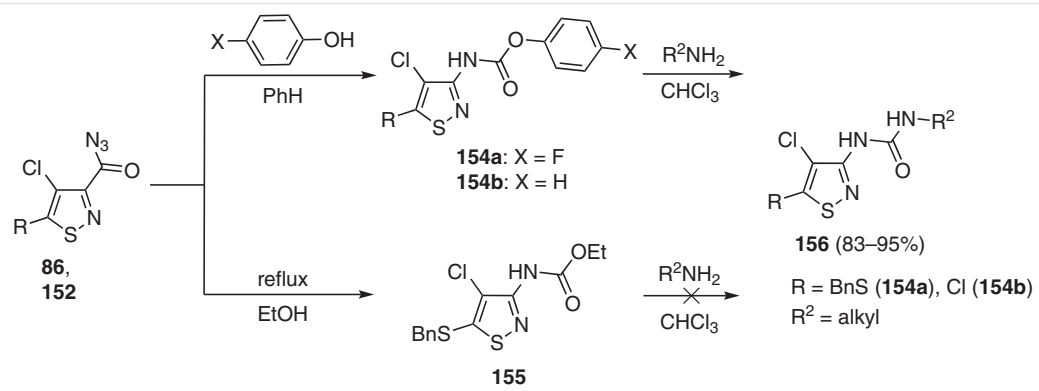

Scheme 54 Synthesis and modification of isothiazolylcarbamates 


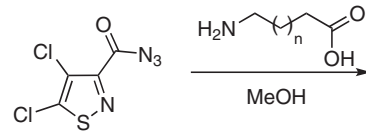

86

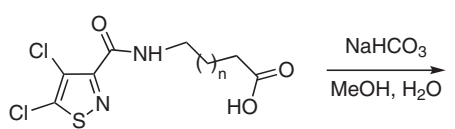

$158(86-89 \%)$

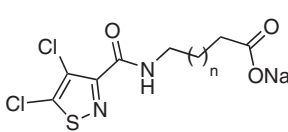

$159(98 \%)$

Scheme 56 Synthesis of 4,5-dichloroisothiazolic amides of $\gamma$-aminobutyric and $\varepsilon$-aminocaproic acids, $n=1,3$ (yield is $98 \%$ in both cases)

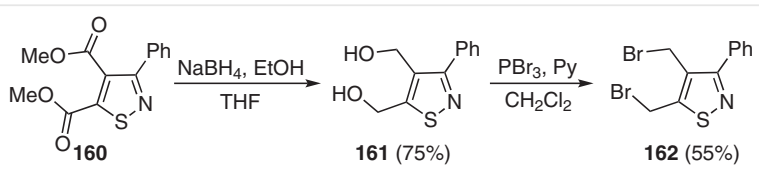
Nal $\mid$ DMF<smiles>COC(=O)c1cc2c(-c3ccccc3)nsc2cc1C(=O)O</smiles>
$\frac{[\mathrm{O}]}{-2 \mathrm{H}}[\mathrm{M}$

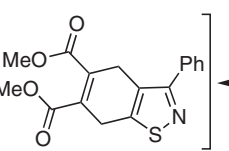

164

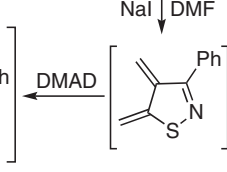

163

Scheme 57 A promising approach towards substituted benz[d]isothiazole

resulting 4,5-bis(bromomethyl)-3-phenylisothiazole (162) with sodium iodide in dimethylformamide led to the generation of the highly active diene 163 , which was immediately reacted with dimethyl acetylenedicarboxylate (DMAD). The resulting adduct 164 was oxidized with atmospheric oxygen to form the benz[d]isothiazole derivative $\mathbf{1 6 5}$. The proposed approach provides access to quite a wide range of substituted benz $[d]$ isothiazoles, and is expected to find future applications in the synthesis of many biologically active derivatives of benz $[d]$ isothiazole.

As an example of other methods for condensed isothiazole derivatives, we should cite the synthesis of the fungicide phytoalexin brassilexin along with its analogues $\mathbf{1 6 6}$, which also exhibit antifungal activity and contain the isothiazole cycle. One of the proposed strategies for the synthesis of these compounds is the Vilsmeier formylation of substituted indolin-2-thiones $\mathbf{1 6 7}$, followed by treatment with aqueous ammonia and oxidation of the extracted imines 168 with iodine in pyridine (Scheme 58). ${ }^{119}$<smiles>[R]c1cc2c(cc1[R])NC(=S(N)O[Na])C2</smiles>
167

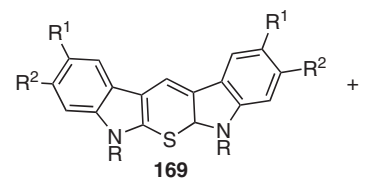

$\mathrm{R}=\mathrm{H}, \mathrm{Me}, \mathrm{OMe}$

$\mathrm{R}^{1}=\mathrm{Me}, \mathrm{OMe}, \mathrm{F}, \mathrm{Cl}, \mathrm{Br}, \mathrm{H}$

$\mathrm{R}^{2}=\mathrm{Me}, \mathrm{OMe}, \mathrm{F}, \mathrm{Cl}, \mathrm{Br}, \mathrm{H}$<smiles>[R]c1cc2c(cc1[R])C(C=N)C(=S)N2</smiles>
$\mathrm{I}_{2} \mid \mathrm{Py}$<smiles>[R]c1cc2[nH]c3sncc3c2cc1[R]</smiles>

$166(40-71 \%)$
Scheme 58 Synthesis of brassilexin and its analogues
The formation of by-products 169 was observed during the formylation stage of the reaction, and so the imines $\mathbf{1 6 8}$ together with impurities were introduced into the oxidation reaction with iodine, and the impurities were removed during purification of the target products $\mathbf{1 6 6}$.

An alternative strategy was proposed for the synthesis of brassilexin (166a) through the formylation of indolin-2one (170), followed by heterocyclization of the resulting 2bromo- $1 H$-indole-3-carbaldehyde (171) in a reaction with urea and sodium thiocyanate under microwave irradiation (Scheme 59). ${ }^{120}$ This strategy has also been successfully applied in the synthesis of isothiazole-containing steroids. ${ }^{120}$

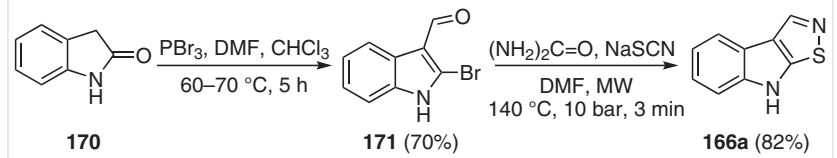

Scheme 59 An alternative way for the synthesis of fungicide brassilexin

Isothiazoles condensed with pyrazole rings were found to be promising biologically active compounds with fungicidal properties. ${ }^{121,122}$ For their synthesis, a strategy has been reported consisting of the oxidation of 1-aryl-5-amino-3-methylpyrazole-4-carboxylic acid thioamides $\mathbf{1 7 2}$ with hydrogen peroxide in pyridine, leading to good yields of the desired 3-aminopyrazolo[3,4-c]isothiazoles 173 (Scheme 60). In this case, nitrile $\mathbf{1 7 4}$ was formed in trace amounts. At the same time, the use of iodine as an oxidizing agent in a tetrahydrofuran medium resulted in the formation of either only product $\mathbf{1 7 4}$ or a mixture of products with a predominance of the 4-cyano derivative $\mathbf{1 7 4}$ in a ratio of 95:5. In the case of a 2,5-dichlorophenyl derivative, the corresponding nitrile was the main oxidation product. Some of these synthesized 5-aminopyrazolo[3,4-c]isothiazoles have been shown to be promising as safe antidermatophytic drug candidates. ${ }^{123}$
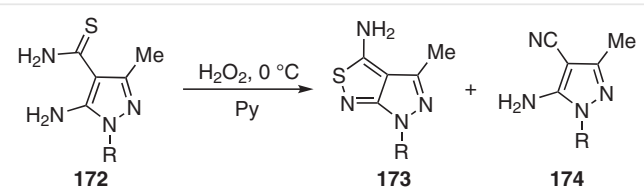

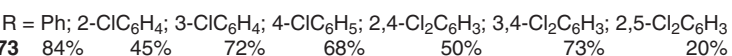
$\mathrm{R}=3-\mathrm{O}_{2} \mathrm{NC}_{6} \mathrm{H}_{4} ; 4-\mathrm{O}_{2} \mathrm{NC}_{6} \mathrm{H}_{4} ; t-\mathrm{C}_{4} \mathrm{H}_{9}$

Yield $173 \quad-75 \% \quad 95 \% \quad 35 \%$

Scheme 60 Oxidation of 5-aminopyrazole-4-carboxylic acid thioamides leading to 3-aminopyrazolo[3,4-c] isothiazole system 
The interaction of 5-aminopyrazoles 175 with Appel's salt (176) represents another approach to the synthesis of condensed heterocyclic systems (Scheme 61), and pyrazole derivatives of 1,2,3-dithiazole 177 and substituted pyrazolo[3,4-c]isothiazole-3-carbonitriles $\mathbf{1 7 8}$ have been observed, ${ }^{124}$ rather than pyrazolo[3,4-d]thiazole-3-carbonitriles as previously believed. ${ }^{125}$

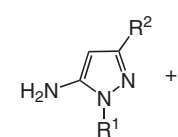

$R$
175

$\mathrm{R}^{1}=\mathrm{H}, \mathrm{Me}, t-\mathrm{Bu}, \mathrm{Bn}, \mathrm{Ph}$

$\mathrm{R}^{2}=\mathrm{Me}, \mathrm{Ph}$

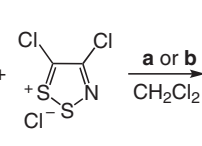

a:

a: $\overbrace{\mathrm{Ne}}$

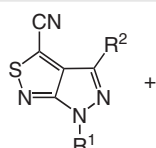

$\mathrm{I}^{1}$

$177(7-57 \%)$

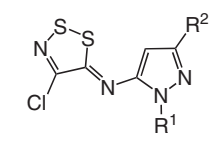

178 (up to $92 \%$ )

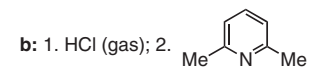

Scheme 61 Investigation of the reaction between 5-aminopyrazoles and Appel's salt

The yields of compounds $\mathbf{1 7 7}$ and $\mathbf{1 7 8}$ depend on the temperature, reaction time, acidity of the reaction mixture, and substituents on the pyrazole ring. When substituted $1 H$-pyrazoles were introduced into the reaction, the main products were pyrazole derivatives of 1,2,3-dithiazole, regardless of the reaction conditions, and pyrazolo[3,4-d]isothiazole-3-carbonitriles did not form. This is particularly interesting because from the corresponding pyrazole derivatives of 1,2,3-dithiazole, it is possible to synthesize thiazoles isomeric to isothiazoles 177 by thermolysis, which may be convenient in the process of synthesizing libraries of compounds for biological screening.

\section{Isothiazoles in the Synthesis of Transition- Metal Complexes and in Metal-Complex Ca- talysis}

The properties manifested by metal complexes are largely determined by the ligand environment of the metal, which ensures the creation of a specific distribution of the electron density on the metal atom and the formation of a spatial framework around it. Information about the metal complexes of the isothiazole series is sparse and fragmentary, and techniques for their practical application have been studied only as isolated examples.

The first information regarding such metal complexes, published in two articles in 1971, was devoted to the synthesis and study of the structure of $\mathrm{Co}(\mathrm{II}), \mathrm{Ni}(\mathrm{II}), \mathrm{Cu}(\mathrm{II})$ and $\mathrm{Pt}$ (II) complexes with unsubstituted isothiazole as a ligand. ${ }^{126,127}$

For cobalt, complexes $\mathrm{CoX}_{2} \mathrm{~L}_{2}, \mathrm{CoX}_{2} \mathrm{~L}_{4}$ and $\left[\mathrm{CoL}_{6}\right]\left(\mathrm{ClO}_{4}\right)_{2}$ were obtained, where $\mathrm{L}$ is an unsubstituted isothiazole and $\mathrm{X}=\mathrm{Cl}, \mathrm{Br}$, I. ${ }^{126}$ The characterizations of their structures was accomplished by using elemental analysis, diffuse reflectance spectroscopy, magnetic susceptibility, conductivity in solution, and IR spectroscopy. $\mathrm{CoCl}_{2} \mathrm{~L}_{2}$ and $\mathrm{CoBr}_{2} \mathrm{~L}_{2}$ complex- es are polymer structures, $\mathrm{CoCl}_{2} \mathrm{~L}_{4}$ and $\mathrm{CoBr}_{2} \mathrm{~L}_{4}$ are octahedral, and $\mathrm{CoI}_{2} \mathrm{~L}_{2}$ and $\mathrm{CoI}_{4} \mathrm{~L}_{2}$ are tetrahedral, but in solution all complexes are characterized by a tetrahedral structure. For the $\mathrm{CoI}_{4} \mathrm{~L}_{2}$ complex, instability with regard to the action of atmospheric oxygen and decomposition in nitromethane solution with the formation of molecular iodine and the $\mathrm{CoI}_{2} \mathrm{~L}_{2}$ complex were observed. The $\left[\mathrm{CoL}_{6}\right]\left(\mathrm{ClO}_{4}\right)_{2}$ complex is assigned an octahedral structure, both in solid form and in nitromethane solution, with the perchlorate anion in the outer sphere of the complex. Based on the electronic and IR spectra, it was suggested that isothiazole is coordinated through a nitrogen atom. ${ }^{126}$

In the other paper published in $1971,{ }^{127}$ the trans$\mathrm{Co}(\mathrm{NCS})_{2} \mathrm{~L}_{4}$ complex was obtained, to which the octahedral structure was also attributed as a result of magnetic susceptibility data. The hypothesis of the trans-form of the complex is suggested based on the reaction with $\alpha, \alpha^{\prime}$-dipyridyl, leading to the formation of a $\mathrm{Co}(\mathrm{NCS})_{2}$ (bipy) $)_{2}$ complex as a result of ligand exchange. The same paper describes the synthesis of complexes $\mathrm{CuCl}_{2} \mathrm{~L}_{2}, \mathrm{CuBr}_{2} \mathrm{~L}_{2}, \mathrm{Cu}\left(\mathrm{NO}_{3}\right)_{2} \mathrm{~L}_{2}$, $\left[\mathrm{LH}^{+}\right]_{2}\left[\mathrm{CuOCH}_{2} \mathrm{CH}_{3}\left(\mathrm{NO}_{3}\right)_{3} \mathrm{~L}_{2}\right]$ (unstable), $\mathrm{Cu}\left(\mathrm{NO}_{3}\right)_{2} \mathrm{~L}_{4}, \mathrm{NiCl}_{2} \mathrm{~L}_{4}$, $\mathrm{NiBr}_{2} \mathrm{~L}_{2}, \mathrm{Ni}\left(\mathrm{ClO}_{4}\right)_{2} \mathrm{~L}_{6}$, and cis- $\mathrm{PtCl}_{2} \mathrm{~L}_{2}$. The synthesized complexes were characterized using IR spectroscopy, elemental analysis, magnetic susceptibility, and powder X-ray diffraction. For complexes of the $\mathrm{MHal}_{2} \mathrm{~L}_{2}$ type [M = Cu(II), $\mathrm{Co}(\mathrm{II})$; $\mathrm{Hal}=\mathrm{Cl}, \mathrm{Br}]$ and for $\mathrm{NiBr}_{2} \mathrm{~L}_{2}$, a polymer octahedral structure with bridging halogen atoms and isothiazole in the trans position was proposed, while complexes $\mathrm{NiCl}_{2} \mathrm{~L}_{4}$, $\mathrm{Cu}\left(\mathrm{NO}_{3}\right)_{2} \mathrm{~L}_{4}, \mathrm{Cu}\left(\mathrm{NO}_{3}\right)_{2} \mathrm{~L}_{2}$, and $\mathrm{Ni}\left(\mathrm{ClO}_{4}\right)_{2} \mathrm{~L}_{6}$ were characterized as octahedral. For cis- $\mathrm{PtCl}_{2} \mathrm{~L}_{2}$, a cis-planar configuration was proposed with coordination through the nitrogen atom of the cycle. Later, various cobalt and nickel complexes with 3, 4- and 5-methylisothiazoles were studied in detail. ${ }^{128,129}$ It was also shown that 3-methylisothiazole was only able to form tetrahedral complexes of the $\mathrm{MeX}_{2} \mathrm{~L}_{2}$ type, which was associated with steric hindrance created by the methyl group at position 3 of the heterocycle. The isothiazole nuclei in all the synthesized complexes are coordinated through a nitrogen atom.

The same researchers obtained $\mathrm{Pd}(\mathrm{II}), \mathrm{Pt}(\mathrm{II}), \mathrm{Rh}(\mathrm{III})$, and Ir(III) complexes with isothiazole and 3-, 5-methylisothiazoles: $\mathrm{PdX}_{2} \mathrm{~L}_{2}(\mathrm{X}=\mathrm{Cl}, \mathrm{Br}$; $\mathrm{L}=$ isothiazole, 3-methylisothiazole, 5-methylisothiazole), $\mathrm{PtCl}_{2} \mathrm{~L}_{2}$ (L = isothiazole, 3-methylisothiazole, 5-methylisothiazole), $\mathrm{RhCl}_{3} \mathrm{~L}_{3}$ ( $\mathrm{L}=$ isothiazole, 3-methylisothiazole, 5-methylisothiazole), $\mathrm{RhCl}_{3} \mathrm{~L}_{4}(\mathrm{~L}$ = 5-methylisothiazole), $\operatorname{IrCl}_{3} \mathrm{~L}_{3}$ ( $\mathrm{L}=3$-methylisothiazole, 5methylisothiazole), and $\operatorname{IrCl}_{3} \mathrm{~L}_{4}$ ( $\mathrm{L}=$ isothiazole). ${ }^{130}$ The unsubstituted isothiazoles in the complexes are coordinated via a sulfur atom, while 3-methylisothiazole is coordinated via a nitrogen atom. 5-Methylisothiazole was coordinated through a nitrogen atom in the $\mathrm{Pd}(\mathrm{II})$ and $\mathrm{Rh}(\mathrm{III})$ complexes, and in the $\mathrm{Pt}(\mathrm{II})$ and $\mathrm{Ir}(\mathrm{III})$ complexes through a sulfur atom.

The literature describes only one example of an isothiazole-containing complex with $\mathrm{PdCl}_{2}$, the structure of which was accurately determined by X-ray crystal structure 
analysis (Figure 3). ${ }^{131}$ In this complex, palladium had a planar environment with trans-oriented benzo[ $d]$ isothiazole ligands.

As part of studying the ability of 1,2-azoles to form metal complexes, stability studies of isothiazole complexes with cobalt(II), nickel(II), copper(II), zinc(II), and silver(I) were carried out by potentiometric and photocolorimetric methods. ${ }^{132}$ The stability of the complexes varies in the series of 1,2-azoles as follows: pyrazole > isothiazole > isoxazole. It was suggested that the higher stability of the isothiazole complexes in comparison with their isoxazole analogues could be explained by the possibility of additional $\pi$ bond formation between the isothiazole and the metal cation due to the presence of an unoccupied d-orbital on the sulfur atom in the heterocycle.

The literature describes bimetallic tetraselenocyanate complexes of cobalt(II), nickel(II), cadmium(II), and mercury(II), in which isothiazole, 4-methylisothiazole, and 4-benzylisothiazole act as ligands. ${ }^{133,134}$ Assumptions about the structures of these complexes were made based on elemental analysis, UV-VIS and IR spectroscopy, magnetic susceptibility, and the HSAB theory, wherein a single monomer complex $\mathrm{L}_{2} \mathrm{Ni}(\mathrm{NCSe})_{2} \mathrm{Hg}(\mathrm{NCSe})_{2}$ (L= methylisothiazole, with selenocyanate acting as a bridging ligand) was separated, in which nickel was in an octahedral environment, probably due to the axial coordination of the selenocyanate fragments of the upper layers. All other bimetallic complexes of different composition are described as polymeric tetrahedral, where the selenocyanate acts as a bridging ligand, the $\mathrm{N}$-terminus is coordinated on cobalt and nickel, and the Seterminus is coordinated on cadmium and mercury. Coordination of isothiazoles occurs in these cases via a nitrogen atom at the axial positions in the case of $\mathrm{Ni}(\mathrm{II})$ and $\mathrm{Co}(\mathrm{II})$, or through sulfur in the case of $\mathrm{Cd}(\mathrm{II})$ and $\mathrm{Hg}(\mathrm{II})$.

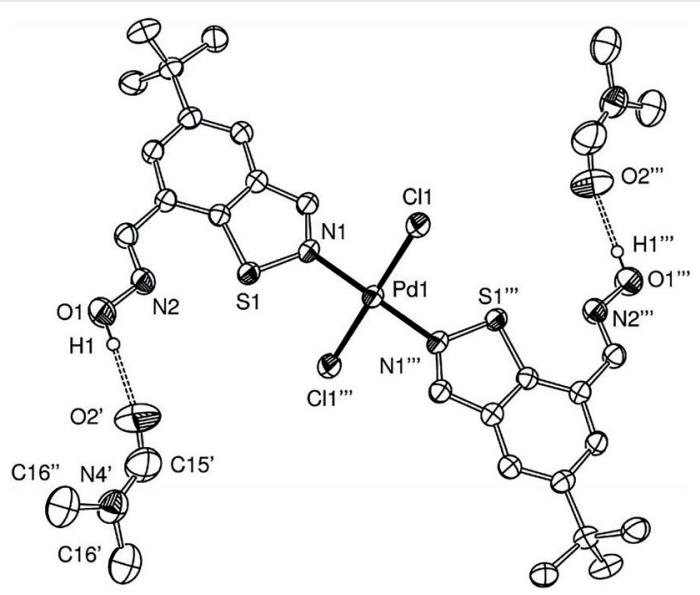

Figure 3 The structure of a single palladium complex of isothiazole as confirmed by $\mathrm{X}$-ray crystal structure analysis (reproduced with permission) $)^{131}$
Data on isothiazole-containing carbonyl complexes of tungsten $\mathrm{L}_{\mathrm{x}} \mathrm{W}(\mathrm{CO})_{6-\mathrm{x}}$, molybdenum $\mathrm{LMo}\left(\mathrm{CO}_{5}\right)$, and chromium $\mathrm{L}_{\mathrm{x}} \mathrm{Cr}(\mathrm{CO})_{6-\mathrm{x}}$ ( $\mathrm{L}$ is the isothiazole ligand; $\mathrm{x}=1,2$ ), obtained by ligand exchange from the hexacarbonyl of the corresponding metal and isothiazole, 4-methylisothiazole or 5-methylisothiazole under ultraviolet irradiation, have been published. ${ }^{135,136}$ At the same time, depending on the irradiation time of the reaction mixture, substitution of one to two carbonyl fragments in the starting metal hexacarbonyl has been observed. Based on IR spectra, it has been established that the synthesized complexes have a $C 4_{v}$ symmetry group, and based on mass spectrometric data for the fragmentation of $\mathrm{L}_{\mathrm{x}} \mathrm{W}(\mathrm{CO})_{6-\mathrm{x}}$ and $\mathrm{L}_{\mathrm{x}} \mathrm{Cr}(\mathrm{CO})_{6-\mathrm{x}}$ complexes and the starting isothiazole ligands, it has been found that in all cases, the coordination was achieved through the nitrogen atom. ${ }^{136}$ This was also consistent with the ${ }^{1} \mathrm{H}$ NMR data for the synthesized complexes. An attempt was made to synthesize the isothiazole $\pi$-complex based on the triacetonitrile tricarbonyl complex of chromium $\left[\left(\mathrm{CH}_{3} \mathrm{CN}\right)_{3} \mathrm{Cr}(\mathrm{CO})_{3}\right]$, but an unstable product was separated with an $\mathrm{L}_{3} \mathrm{Cr}(\mathrm{CO})_{3}(\mathrm{~L}$ = isothiazole) structure, according to IR spectroscopy data. ${ }^{136}$

Finally, some examples of isothiazole complexes, in which the metal is coordinated not only through ring heteroatoms, but also through heteroatoms of exocyclic groups, are known. Thus, diperchlorate isothiazole complex 179 was obtained by treatment of $\Delta$-bis(ethylenediamine)threoninatocobalt(III) trifluoromethansulfonate $\mathbf{1 8 0}$ with thionyl chloride in dimethylformamide, followed by ion exchange chromatography. In this case, the isothiazole3-carboxylic acid acts as a bidentate ligand, chelating cobalt through the heterocyclic nitrogen atom and carboxyl group (Scheme 62). ${ }^{137}$

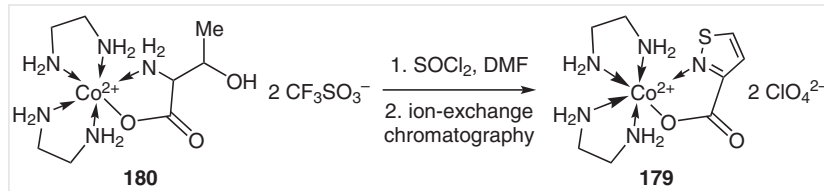

Scheme 62 Formation of the isothiazole ring in cobalt chelate

The structure of the complex was confirmed by X-ray crystal structure analysis. Threonine serves as the starting material for the formation of the isothiazole ring. In this case, thionyl chloride acts as both a dehydrating agent and a sulfur atom donor for the isothiazole heterocycle. It is assumed that in the first stage of this reaction, cobalt-chelating threonine chloride is formed, with a sufficiently acidic proton on the $\alpha$-carbon atom, which makes it possible to proceed with subsequent transformations.

In order to obtain the isothiazole complexes, Meyer et al. ${ }^{138}$ synthesized isothiazoles containing exocyclic chelating fragments. Thus, pyridine-containing azomethines 181a and 181b were prepared from 5-formyl-3-methylisothiazole (182) (Scheme 63). 


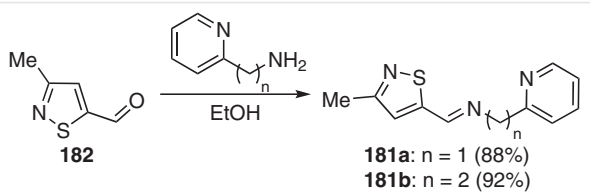

Scheme 63 Synthesis of ligands with isothiazolic and pyridinic cores

In addition to this, sulfide $\mathbf{1 8 3}$ was synthesized via the lithiation of 3,5-dimethylisothiazole (184) (Scheme 64). Also, 3-bromomethyl-5-methylisothiazole (185) was obtained starting from 3,5-dimethylisothiazole (184) through bromination of the methyl group at position 3 . The introduction of isothiazole 185 into the reaction with $N, N, N^{\prime}, N^{\prime}-$ tetraethyldiethylenetriamine led to the formation of amine 186.

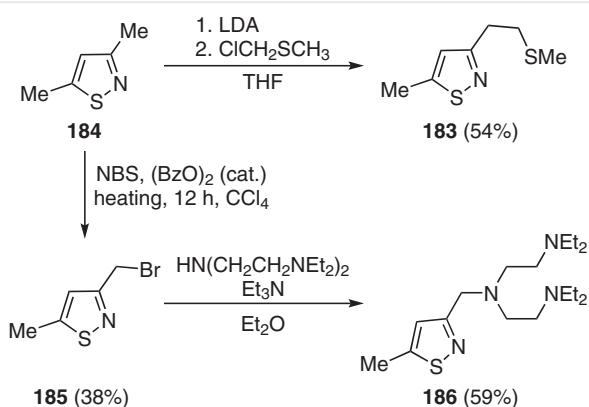

Scheme 64 Preparation of 3-substituted isothiazoles from 3,5-dimethylisothiazole

Based on the synthesized isothiazoles, binuclear isothiazole-containing silver triflate complexes $\left[\mathrm{LAgOSO}_{2} \mathrm{CF}_{3}\right]_{2}(\mathrm{~L}$ = 181a, 181b, 183) and $[\mathrm{LAg}]_{2}\left[\mathrm{O}_{3} \mathrm{SCF}_{3}\right]_{2}(\mathrm{~L}=186)$ were obtained. The structures of the complexes were established by $\mathrm{X}$-ray crystal structure analysis in all cases, except for the complex with ligand 181a. In the case of $L=183,186$, ligands were coordinated to the silver atom by the nitrogen atom of the heterocycle and exocyclic heteroatoms (nitrogen or sulfur). In the case of $L=\mathbf{1 8 1 b}$, the silver coordination occurs exclusively on the exocyclic heteroatoms (through the nitrogen of the azomethine and pyridine fragments).

Metal complexes with $\mathrm{Cu}(\mathrm{II})$ were obtained based on 4,5-dichloroisothiazole-3-carboxylic acid, its amide, and benzotriazolamide. ${ }^{27,139,140}$ Polymer complexes of copper $\left[\mathrm{LCuCl}_{2}\right]_{\mathrm{n}}, \mathrm{LCuBr}_{2}$ ( $\mathrm{L}=$ 4,5-dichloroisothiazole-3-carboxylic acid amide), $\mathrm{Cu}(\mathrm{L})(\mathrm{BtaH})\left(\mathrm{H}_{2} \mathrm{O}\right)_{2}\left(\mathrm{NO}_{3}\right)(\mathrm{L}=4,5$-dichloroisothiazole-3-carboxylic acid, $\mathrm{BtaH}=$ benzotriazole), and (L) $\left(\mathrm{CuH}_{2} \mathrm{O}\right) \mathrm{Cl} \cdot 0.5 \mathrm{H}_{2} \mathrm{O}(\mathrm{L}=4,5$-dichloroisothiazole-3-carboxylate) were synthesized. The complexes were characterized by X-ray crystal structure analysis. In these complexes, isothiazole ligands chelated a copper atom with a nitrogen atom of the heterocycle and with an oxygen atom of an amide or carboxyl group. The complex $\left[\mathrm{Cu}\left(\mathrm{L}_{2}\right) \mathrm{Cl}_{2}\right]_{\mathrm{n}}$ possesses fungicidal properties against the phytopathogenic fungi Botrytis cinerea and Fusarium sp., completely inhibiting the development of the fungi at a concentration of $0.125 \%$, according to biological tests. The $\mathrm{Cu}\left(\mathrm{L}_{2}\right) \mathrm{Br}_{2}$ complex, being added at a $5 \%$ amount relative to the neonicotinoid insecticide imidacloprid, increases by almost 2 times the toxicity of the insecticide toward Colorado potato beetle larvae, which increases the effectiveness of the insecticide and reduces its consumption. ${ }^{139}$ Complexes of 4,5-dichloroisothiazole-3-carboxylic acid ethanolamide with copper bromide and copper chloride were also obtained, and according to XRD data, 4,5-dichloroisothiazol- $N$-(2-hydroxyethyl)-3carboxamide was coordinated to copper(II) in a tridentate manner. In the bidentate cyclic-type complex, it is coordinated on the nitrogen atom of the heterocycle and on the exocyclic oxygen atom of the amide group with the formation of the five-membered metallocycle CuNCO, and also on the oxygen atom of the substituent hydroxy group, and all these bonds form polymer chains. The complex of 4,5-dichloroisothiazole- $N$-(2-hydroxyethyl)-3-carboxamide with copper(II) bromide (Figure 4) can enhance the action of the insecticides cypermethrin and imidacloprid, and at the same time, copper bromide and the ligand separately did not show any similar activity with insecticides. ${ }^{141}$

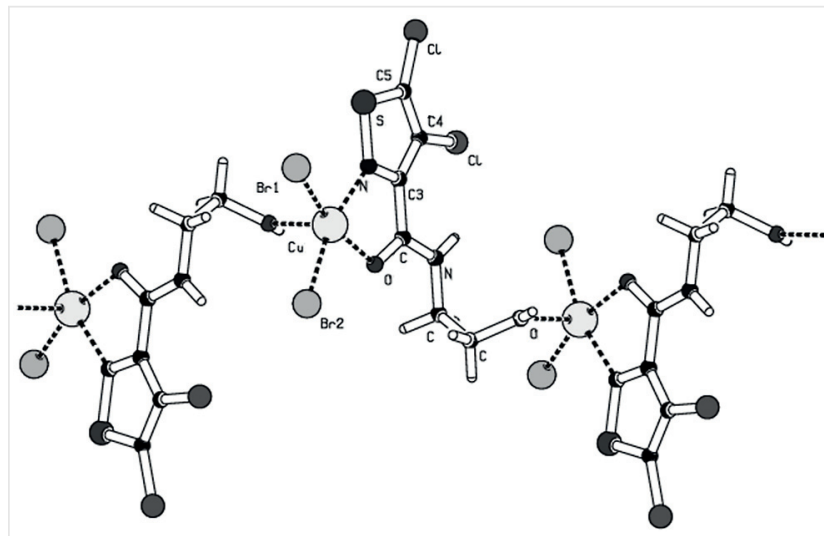

Figure 4 The structure of a polymeric copper complex of 4,5-dichloroisothiazole- $\mathrm{N}$-(2-hydroxyethyl)-3-carboxamide with copper(II) bromide (reproduced with permission). ${ }^{141}$ The structure of the polymer complex with copper chloride is similar.

In 2011, the Pd(II) complex of composition $\mathrm{L}_{2} \mathrm{Pd}(\mathrm{L}=4,5-$ dichloroisothiazole-carboxylate) was synthesized from 4,5dichloroisothiazole-3-carboxylic acid. ${ }^{26}$ It could not be obtained in crystalline form, and therefore, to describe its structure, quantum chemical modeling using the B3LYP1/MIDI(3d) level of theory was used. According to the quantum chemical calculations, a flat-square structure was attributed to the complex; however, it was not possible to establish exactly whether the isothiazole fragments in the complex were in cis- or trans-form due to the proximity of their calculated formation enthalpies. The complex showed catalytic activity in the Suzuki reaction: on addition of 0.1 
mol\% of the complex, the reaction of 2,4-difluorophenylboronic acid with 5-bromosalicylic acid, carried out in water exposed to air at $100^{\circ} \mathrm{C}$, was complete in 15 minutes with a quantitative yield of 5-(2,4-difluorophenyl)-2-hydroxybenzoic acid being obtained. The latter is active pharmaceutical substance diflunisal, a nonsteroidal anti-inflammatory drug (NSAID) with analgesic and antipyretic effects.

The possibility of using isothiazole complexes with palladium(II) as a catalyst for cross-coupling reactions is of particular interest because of its relevance both in practical and scientific terms. Cross-coupling reactions catalyzed by palladium complexes are widely used in modern organic synthesis as a reliable method of forming carbon-carbon bonds in order to produce polyfunctional biaryls, arylated olefins, acetylenes, and their heterocyclic analogs. Compounds of this type are key structural elements of a number of modern drugs, ${ }^{142}$ and are used to develop special purpose polymeric materials. ${ }^{143}$ The Nobel Prize in Chemistry for 2010 was awarded for studies of cross-combination reactions, which attests to their high scientific and practical significance. ${ }^{144}$

The key parameter determining the efficiency of a catalyst in cross-coupling reactions is the nature of the ligand on the palladium complex. Traditionally used phosphine ligands are not suitable for large-scale use due to their toxicity, their ease of oxidation, and their high cost, and therefore, the tendency over the last ten years to use heterocyclic carbenes, oxazolines, Schiff bases, and other nitrogen-containing compounds instead of phosphorus-containing ligands is quite understandable. ${ }^{145}$ At the same time, from the point of view of ecology and large-scale practical applications of cross-coupling reactions, it would be optimal to use water as a reaction medium ('green chemistry'). ${ }^{145-148}$ One of the most important practical examples of cross-coupling reactions is the Suzuki reaction, which involves the coupling of aryl and vinylboronic acids with aryl or vinyl halides, catalyzed by palladium complexes. The possibility of extensive adjustment of the functional environment of the chlorinated isothiazole, as well as the initial data on the successful use of the 4,5-dichloroisothiazole-3-carboxylic acid complex with palladium chloride for the Suzuki reaction in aqueous medium, indicates a high potential for further research into the design and synthesis of isothiazole ligands for palladium complexes.

During the first experiments, two of the most accessible and simple derivatives of 4,5-dichloroisothiazole-3-carboxylic acid, i.e., its hydrazide 187a and phenylhydrazide 187b, were synthesized (Scheme 65). ${ }^{149}$

Palladium complexes of composition 187a. $\mathrm{PdCl}_{2}$ and 187b. $\mathrm{PdCl}_{2}$ were obtained by reacting compounds $187 \mathbf{a}$ and 187b with $\mathrm{Na}_{2} \mathrm{PdCl}_{4}$ in methanol. Their catalytic activity was studied during the Suzuki reaction between 4-methoxyphenylboronic acid (188) (which is prone to pro-

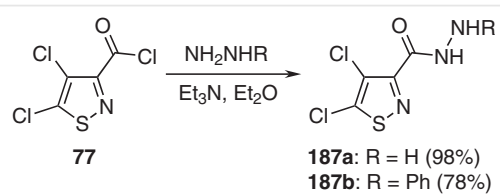

Scheme 65 Preparative synthesis of hydrazides of 4,5-dichloroisothiazole-3-carboxylic acid

todeboronation) and 3-bromobenzoic acid (189). The target product of this reaction is 4'-methoxy[1,1'-biphenyl]-3-carboxylic acid (190) (Scheme 66).

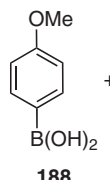

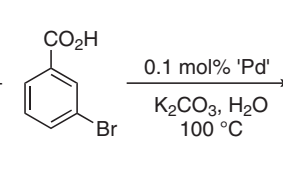

189

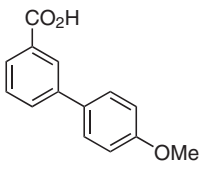

190
Scheme 66 Model reaction - synthesis of 4'-methoxy[1,1'-biphenyl]-3carboxylic acid

As in the case of the palladium complex of acid $\mathbf{7 4}$, the complexes of hydrazide 187a and phenylhydrazide 187b exhibit high catalytic activity in the Suzuki reaction, albeit slightly lower than that of the 4,5-dichloroisothiazole-3carboxylic acid complex with palladium (Table 1). At the same time, the catalytic activity of the hydrazide complex was higher than that of the phenylhydrazide complex.

Table 1 Characteristics of the Cross-Couplings of 3-Bromobenzoic Acid with 4-Methoxyphenylboronic Acid Catalyzed by Complexes of Palladium Chloride with 4,5-Dichloroisothiazole-3-carboxylic Acid (74) ${ }^{\text {a }}$

\begin{tabular}{lcc}
\hline Pd complex & Time $(\mathrm{min})$ & Yield of $\mathbf{1 9 0}(\%)^{\mathrm{c}}$ \\
\hline $\mathbf{( 7 4})_{2} \cdot \mathrm{Pd}^{\mathrm{b}}$ & 15 & 100 \\
$\mathbf{1 8 7 a} \cdot \mathrm{PdCl}_{2}^{\mathrm{c}}$ & 30 & 100 \\
$\mathbf{1 8 7 b} \cdot \mathrm{PdCl}_{2}{ }^{\mathrm{d}}$ & 60 & 96 \\
\hline
\end{tabular}

\footnotetext{
adapted from ref. 149.

b Complex (74) 2 Pd: double salt; $187 \mathrm{a} \cdot \mathrm{PdCl}_{2}$ : hydrazide; $187 \mathrm{a} \cdot \mathrm{PdCl}_{2}$ : phenylhydrazide.

' Determined from ${ }^{1} \mathrm{H}$ NMR data.
}

Detailed studies on the influence of the functional environment of the isothiazole heterocycle on the catalytic activity of the corresponding palladium complexes required the creation of new ligands. For this purpose, several new derivatives were synthesized based on 4,5-dichloroisothiazole-3-carboxylic acid, which contained different substituents at position 3 of the heterocycle as well as additional coordination centers of various nature.

For this purpose, heterocyclic molecules containing 1,2,4-triazole or tetrazole rings together with an isothiazole fragment have been synthesized. ${ }^{150}$ To construct a triazole heterocycle and to obtain (isothiazole)triazoles, an 
approach including initial synthesis of amidrazone 191 via the reaction of nitrile $\mathbf{8 9}$ with hydrazine hydrate was chosen (Scheme 67).

$$
\text { (80\%) }
$$

Scheme 67 An example of the proposed approach towards (isothiazol-3-yl)triazoles

In order to obtain the target amidrazone, it was found that the reaction should be carried out with a minimal amount of methanol or without solvent at all, because otherwise the hydrazine hydrate does not react with the nitrile 89. Amidrazone 191 was further treated with acetyl chloride in the presence of triethylamine, and the resulting acyl derivative 192 was subjected to cyclization to give the target 1,2,4-triazolylisothiazole 193 by heating in glacial acetic acid followed by neutralization of the reaction mixture with $\mathrm{KOH}$ solution (Scheme 67). The yield of 1,2,4-triazolyl(isothiazole) 193 was 85\%.

The nitrile group of carbonitriles 89 and $\mathbf{9 2 b}$ was used for the formation of tetrazole heterocycles (Scheme 68). The synthesis of tetrazolyl isothiazoles 194a,b was carried out by the reaction of sodium azide and ammonium chloride with carbonitriles 89 and $\mathbf{9 2 b}$ in methanol, with good yields being obtained.

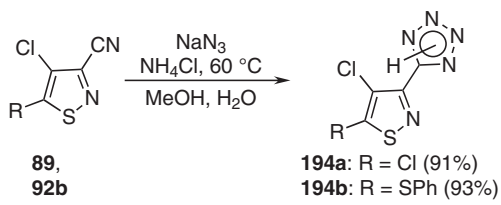

Scheme 68 Synthesis of (isothiazol-3-yl)tetrazoles
The derivative 193 and its precursor amidrazone 191 were used for the synthesis of azole complexes. For a qualitative assessment of the mutual influence of 1,2-azole and triazole fragments in mixed ligands, palladium complexes with 1,2,4-triazole were also obtained. For the synthesized complexes, extremely low solubility was noted in organic solvents and in water, possibly due to their polymer structure, and therefore they were characterized by IR spectroscopy and elemental analysis. The model reactions presented in Scheme 66 were carried out in $50 \%$ aqueous methanol (at $20^{\circ} \mathrm{C}$ and $75^{\circ} \mathrm{C}$ ) or in water (at $100{ }^{\circ} \mathrm{C}$ ) in the presence of $0.1 \mathrm{~mol} \%$ of palladium complexes and potassium carbonate as the base. All reactions were carried out in air in the absence of an inert atmosphere. The results of testing the catalytic activity of the complexes are presented in Table 2.

The resulting complexes, except for $(\mathbf{1 9 1})_{2} \cdot \mathrm{PdCl}_{2}$, $(\mathbf{1 9 4 b})_{2} \cdot \mathrm{PdCl}_{2}$ and $(1,2,4 \text {-triazole })_{2} \cdot \mathrm{PdCl}_{2}$, exhibited high catalytic activity at elevated temperatures (i.e., $75^{\circ} \mathrm{C}$ or $100{ }^{\circ} \mathrm{C}$ ). The palladium complexes with the isothiazole ligands 191 and 193 were inert at room temperature, while the $(\mathbf{1 9 1})_{2} \cdot \mathrm{PdCl}_{2}$ complex remained inactive even when heated, as did the (1,2,4-triazole $)_{2} \cdot \mathrm{PdCl}_{2}$ complex. The $(\mathbf{1 9 4 b})_{2} \cdot \mathrm{PdCl}_{2}$ complex exhibited only a slight catalytic activity at $100{ }^{\circ} \mathrm{C}$.

Later, the corresponding 3,5-isoxazolyl(isothiazolyl)substituted 1,2,4-oxadiazoles 195a-c were synthesized by successive transformations of 5-(4-methylphenyl)isoxazole-3-carboxylic acid amidoxime 95 and 4,5-dichloroisothiazole-3-carboxylic acid amidoxime 196 (Scheme 69). ${ }^{151}$

Additionally, the 2,5-(5-aryl)isoxazolyl(isothiazolyl)substituted 1,3,4-oxadiazoles 197a-c were obtained by selective recyclization of (4,5-dichloroisothiazol-3-yl)tetrazole 194a (Scheme 70).

Dichloromethane was the only solvent suitable for the preparation of complexes with representatives of the synthesized ligands 195 and 197; the palladium benzonitrile complex $(\mathrm{PhCN})_{2} \mathrm{PdCl}_{2}$ was used as the source of palladium. The complexes were characterized by their elemental

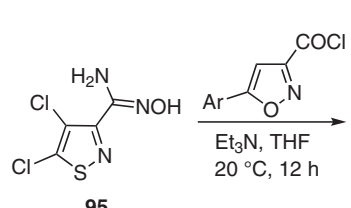

95

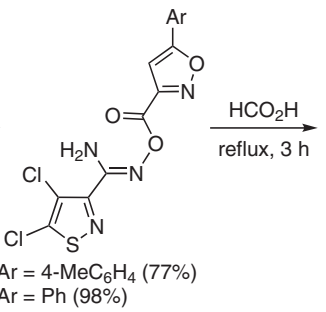

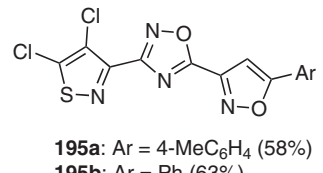

195b: $\mathrm{Ar}=\mathrm{Ph}(63 \%)$

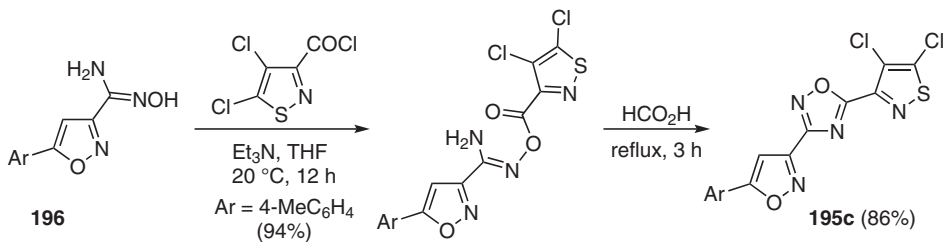

Scheme 69 Synthesis of 3,5-(5-aryl)isoxazol-3-yl(isothiazol-3-yl)-substituted 1,2,4-oxadiazoles 

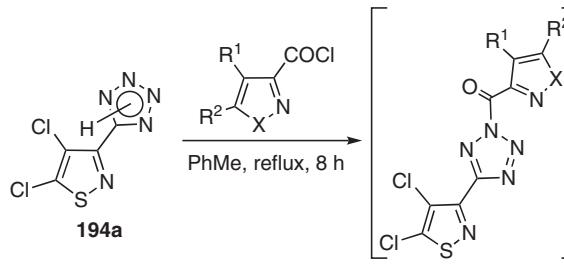

197a: $\mathrm{R}^{1}=\mathrm{R}^{2}=\mathrm{Cl} ; \mathrm{X}=\mathrm{S}(70 \%)$
197b: $\mathrm{R}^{1}=\mathrm{H} ; \mathrm{R}^{2}=4-\mathrm{MeC}_{6} \mathrm{H}_{4} ;$

197b: $R^{1}=H ; R^{2}=4-M$

197c: $R^{1}=H ; R^{2}=P h ; X=O(82 \%)$

Scheme 70 Synthesis 2,5-(5-aryl)isoxazol-3-yl(isothiazol-3-yl)-substituted 1,3,4-oxadiazoles

Table 2 Characteristics of the Cross-Couplings of 3-Bromobenzoic Acid with 4-Methoxyphenylboronic Acid Catalyzed by Complexes of Palladium Chloride with Ligands 191, 193 and 194b

\begin{tabular}{|c|c|c|c|}
\hline Pd complex & $\operatorname{Temp}\left({ }^{\circ} \mathrm{C}\right)$ & Time (min) & Yield of $190(\%)^{b}$ \\
\hline \multirow[t]{2}{*}{$191 \cdot \mathrm{PdCl}_{2}$} & 20 & 20 & traces \\
\hline & 75 & 5 & 97 \\
\hline \multirow[t]{2}{*}{$(191)_{2} \cdot \mathrm{PdCl}_{2}$} & 20 & 20 & traces \\
\hline & 100 & 30 & traces \\
\hline \multirow[t]{2}{*}{ 193. $\mathrm{PdCl}_{2}$} & 20 & 20 & traces \\
\hline & 75 & 5 & 100 \\
\hline \multirow[t]{2}{*}{$(193)_{2} \cdot \mathrm{PdCl}_{2}$} & 20 & 20 & traces \\
\hline & 75 & 5 & 98 \\
\hline \multirow[t]{2}{*}{$(\mathbf{1 9 4 b})_{2} \cdot \mathrm{PdCl}_{2}$} & 20 & 120 & 0 \\
\hline & 100 & 5 & 5 \\
\hline \multirow[t]{2}{*}{ 1,2,4-triazole $\cdot \mathrm{PdCl}_{2}$} & 20 & 20 & 10 \\
\hline & 75 & 5 & 100 \\
\hline \multirow[t]{2}{*}{$(1,2,4 \text {-triazole })_{2} \cdot \mathrm{PdCl}_{2}$} & 20 & 240 & 0 \\
\hline & 100 & 240 & 0 \\
\hline
\end{tabular}

adapted from ref. 150 with permission from Springer Nature.

${ }^{\mathrm{b}}$ Determined from ${ }^{1} \mathrm{H}$ NMR data.

analyses and IR spectroscopic data. In a model Suzuki reaction between 4-methoxyphenylboronic acid (188) and 3-bromobenzoic acid (189) (Scheme 71), it was shown that palladium complexes with these ligands exhibited high catalytic activity in aqueous and aqueous-alcoholic media (Table 3).

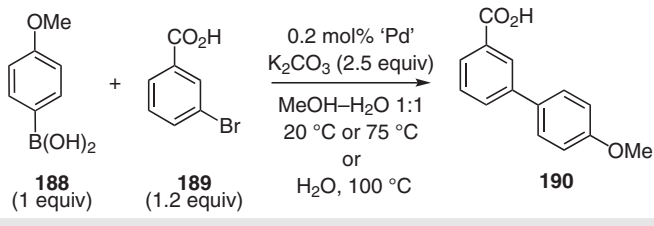

Scheme 71 The model reaction for (isothiazol-3-yl)oxadiazoles palladium complexes catalytic activity testing

As another promising group of ligands for metal complexes, $N$-aryl(isothiazol-3-yl)methyleneimines (aromatic azomethines) and amines were synthesized. ${ }^{152,153}$ Conden-
Table 3 Yields of the Suzuki Reaction Product 4'-Methoxybiphenyl-3carboxylic Acid (190) Depending on the Pd Complex and Reaction Conditions $^{\mathrm{a}}$

\begin{tabular}{|c|c|c|c|c|}
\hline Experiment & Pd complex & Temp $\left({ }^{\circ} \mathrm{C}\right)$ & Time (min) & Yield of $190(\%)^{b}$ \\
\hline 1 & $195 \mathrm{c} \cdot 2 \mathrm{PdCl}_{2}$ & 20 & 15 & 30 \\
\hline 2 & $195 \mathrm{c} \cdot 2 \mathrm{PdCl}_{2}$ & 75 & 5 & 84 \\
\hline 3 & $195 \mathrm{c} \cdot 2 \mathrm{PdCl}_{2}$ & 100 & 1 & 100 \\
\hline 4 & 197a. $\mathrm{PdCl}_{2}$ & 20 & 15 & 0 \\
\hline 5 & 197a. $\mathrm{PdCl}_{2}$ & 75 & 15 & 35 \\
\hline 6 & 197a. $\mathrm{PdCl}_{2}$ & 100 & 50 & 93 \\
\hline 7 & $197 \mathbf{b} \cdot 2 \mathrm{PdCl}_{2}$ & 20 & 20 & 29 \\
\hline 8 & $197 \mathbf{b} \cdot 2 \mathrm{PdCl}_{2}$ & 75 & 5 & 79 \\
\hline 9 & $197 \mathrm{~b} \cdot 2 \mathrm{PdCl}_{2}$ & 100 & 5 & 100 \\
\hline 10 & $(\mathrm{PhCN})_{2} \mathrm{PdCl}_{2}$ & 20 & $\begin{array}{l}15 \\
4 \mathrm{~h}\end{array}$ & $\begin{array}{l}79 \\
90\end{array}$ \\
\hline 11 & $(\mathrm{PhCN})_{2} \mathrm{PdCl}_{2}$ & 75 & 15 & 96 \\
\hline
\end{tabular}

sation of 4,5-dichloroisothiazol-3-carbaldehyde (106) with 4-aminobiphenyl and 1-naphthylamine in methanol in the presence of glacial acetic acid resulted in $85 \%$ yields of azomethines 198a,b (Scheme 72). In the case of the 4-aminobenzoic acid ethyl ester, this technique was not useful due to only trace amounts of the target azomethine being formed. When carrying out the reaction in boiling benzene in the presence of catalytic amounts of glacial acetic acid, incomplete conversion of the starting aldehyde 106 into azomethine $198 \mathrm{c}$ ( $40 \%$ ) was observed, therefore the process was carried out with higher-boiling toluene and an increased amount of acetic acid was used.

Azomethines 198a-c were further reduced to give amines 199a-c by the action of sodium borohydride and acetic acid in benzene, in 94-95\% yields (Scheme 72). Reduction of the isothiazole-containing azomethine $198 \mathrm{c}$ proceeded only when the reaction mixture was boiled; at room temperature, there were no signs of the reaction occurring. Amine 199c was further hydrolyzed into isothiazole amino acid $\mathbf{2 0 0}$ (Scheme 73). 


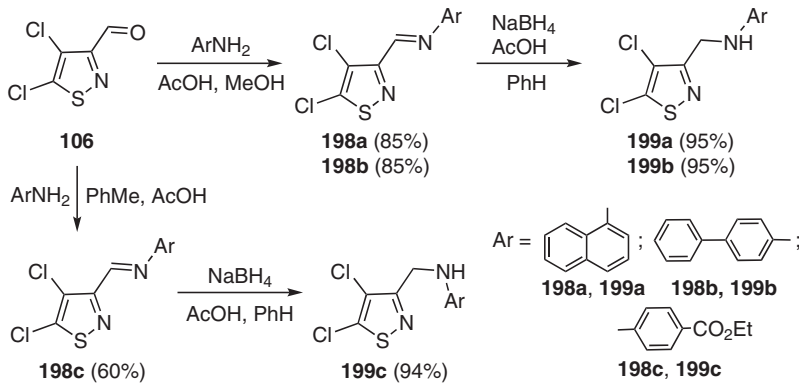

Scheme 72 Synthesis of $\mathrm{N}$-aryl(isothiazol-3-yl)methyleneimines (aromatic azomethines) and amines

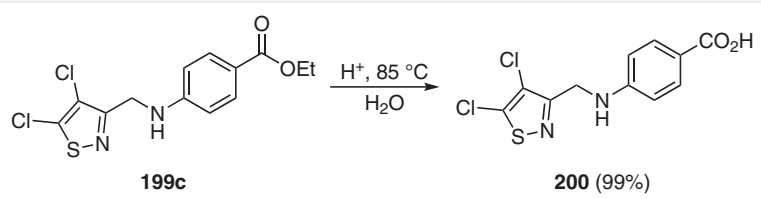

Scheme 73 Deprotection of carboxylic group in compound 199c

Azomethine 198b, amine 199b, and isothiazole-containing amino acid $\mathbf{2 0 0}$ (from the synthesized aromatic azomethines and amines) were used as ligands in order to obtain palladium(II) complexes by reaction with sodium tetrachloropalladate. Complexes of the composition $\mathrm{LPdCl}_{2}$ were formed by the interaction of equimolar amounts of sodium tetrachloropalladate and the ligands in methanol at $20^{\circ} \mathrm{C}$. Since acid $\mathbf{2 0 0}$ was poorly soluble in both methanol and acetonitrile, which were previously used to produce 1,2-azole palladium complexes, the complex was synthesized in a mixture of methanol and DMF, in which derivative $\mathbf{2 0 0}$ is quite soluble. The obtained palladium complexes 198b $\cdot \mathrm{PdCl}_{2}, \mathbf{1 9 9 b} \cdot \mathrm{PdCl}_{2}$, and 200.PdCl${ }_{2}$ were identified

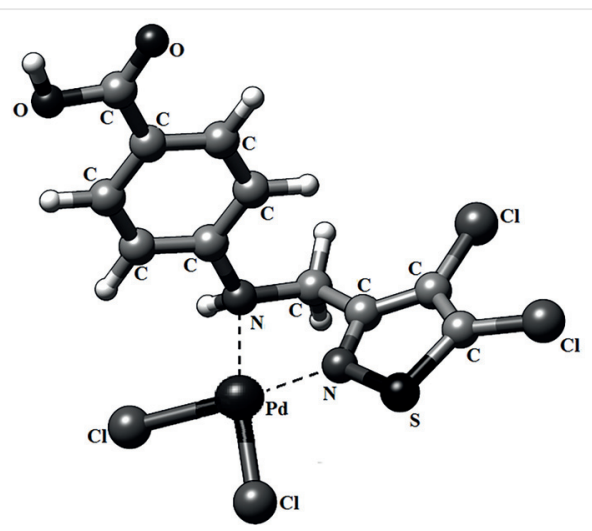

Figure 5 Structure of the complex of isothiazole-containing aromatic amino acid $\mathbf{2 0 0}$ with palladium chloride, obtained using quantumchemical modeling at the B3LYP/6-31+G* /LANL2TZ(f)ECP(Pd) level of theory (reproduced with permission from Springer Nature) ${ }^{153}$ based on their elemental analyses as well as IR spectroscopic data, in which the characteristic vibration bands of the $\mathrm{C}=\mathrm{N}$ and $\mathrm{C}=\mathrm{C}$ bonds of the isothiazole heterocycle and the corresponding exocyclic fragments were apparent. According to their elemental analyses, they form complexes with palladium chloride with the composition $\mathrm{LPdCl}_{2}$. The complexes are insoluble in organic solvents and in water, which made it impossible to record their NMR spectra or to grow single crystals for X-ray crystal structure analysis. The assumption of their structure was made by analogy with the previously obtained palladium complexes with oxime ligands of the isoxazole series, ${ }^{26}$ as well as by comparing the IR spectra of the ligands and the corresponding complexes. This indicates the participation of the heterocycle and exocyclic fragments $(\mathrm{C}=\mathrm{N} / \mathrm{C}-\mathrm{NH})$ in coordination with palladium. For the complex of the isothiazole amino acid $\mathbf{2 0 0}$ with palladium chloride, calculations of the geometry and IR spectrum were made at the B3LYP/6-31+G* LANL2TZ(f)ECP(Pd) level of theory. As a result, it was proposed that the isothiazole ligand $\mathbf{2 0 0}$ in the molecules of the complex 200 $\cdot \mathrm{PdCl}_{2}$ is coordinated to palladium in a bidentate cyclic-type manner by the nitrogen atoms of the heterocycle and the exocyclic amino group to form a fivemembered metallocycle (Figure 5).

Evaluation of the catalytic activity of the obtained complexes on the model reaction presented in Scheme 66 was performed under conditions similar to those used in previous tests. ${ }^{149,150}$ The results of the testing of the catalytic activity of the complexes are presented in Table 4.

Table 4 Characteristics of the Cross-Couplings of 3-Bromobenzoic Acid with 4-Methoxyphenylboronic Acid Catalyzed by Palladium Chloride Complexes with Ligands 198b, $199 \mathrm{~b}$ and $200^{\text {a }}$

\begin{tabular}{|c|c|c|c|}
\hline Pd complex & $\operatorname{Temp}\left({ }^{\circ} \mathrm{C}\right)$ & Time (min) & Yield of $190(\%)^{b}$ \\
\hline \multirow[t]{2}{*}{ 198b $\cdot \mathrm{PdCl}_{2}$} & 20 & 30 & 67 \\
\hline & 75 & 20 & 96 \\
\hline \multirow[t]{2}{*}{ 199b. $\mathrm{PdCl}_{2}$} & 20 & 30 & 42 \\
\hline & 100 & 30 & 100 \\
\hline \multirow{2}{*}{$\begin{array}{l}\text { 200. } \cdot \mathrm{PdCl}_{2} \text { (in situ potassium } \\
\text { salt) }\end{array}$} & 35 & 5 & 100 \\
\hline & 100 & 3 & 100 \\
\hline \multirow[t]{2}{*}{$\mathrm{Na}_{2} \mathrm{PdCl}_{4}$} & 20 & 5 & 87 \\
\hline & 20 & 240 & 92 \\
\hline $\mathrm{Na}_{2} \mathrm{PdCl}_{4}$ & 75 & 5 & 99 \\
\hline
\end{tabular}

a Adapted from refs. 152 and 153 with permission from Springer Nature. ${ }^{\mathrm{b}}$ Determined from ${ }^{1} \mathrm{H}$ NMR data.

The reactions were complete in 3-30 minutes with the formation of 4'-methoxy[1,1'-biphenyl]-3-carboxylic acid (190), the target product of the cross-coupling, with yields of $96-100 \%$. In each case, the formation of palladium black did not occur until the end of the reaction. Analysis of the reaction mixtures by TLC at the time of separation of the 
palladium black consistently showed the absence of aryl halide. The solution itself remained almost colorless, which indirectly indicates a low content of colloidal (nanoscale) palladium in the reaction mixture and products.

According to the obtained data, the palladium complexes with one ligand $\left(\mathrm{LPdCl}_{2}\right)$ were significantly more active than those with two ligands $\left(\mathrm{L}_{2} \mathrm{PdCl}_{2}\right)$. The complex with the isothiazole derivative $\mathbf{2 0 0}$ was the most active among all the complexes tested, and its activity was especially noticeable at $20-35^{\circ} \mathrm{C}$. It should also be noted that the formation of a small amount of the arylboronic acid homocoupling product, 4,4'-dimethoxy-1,1'-biphenyl (with yields of $1-3 \%)$, was observed in the reactions in all cases. Since the reactions were carried out in the absence of an inert atmosphere, it is possible that the by-product was formed because of oxidation of the starting arylboronic acid by aerial oxygen during the catalysis with palladium, but the contribution of this process is considered negligible. Complex 200 was used for the preparation of a heterogeneous siliconoxide-supported catalyst, and its catalytic properties were almost as good as the complex itself and it was able to withstand at least 10 catalytic cycles. ${ }^{154}$

The observed temperature dependence of the catalytic activity of the described isothiazole complexes can be used to control the selectivity of the cross-coupling reactions in molecules with several reaction centers. Isothiazole palladium complexes are suitable for chemical and chemical-pharmaceutical processes in cases where the synthesis of the target substances is carried out using the Suzuki reaction and high purity requirements are imposed on the final product.

We are confident that the data on isothiazole-metal complexes summarized above, as well as the information on the catalytic and biological activity of their representatives, can stimulate further research in this very promising area. At the same time, we believe that while the synthesis of new metal complexes of the isothiazole series and the study of their properties definitely deserves the attention of modern researchers, so also does the study of the practical utilization of the isothiazole complexes that were previously described in the literature.

The above information on isothiazole complexes, as far as we know, is comprehensive. In an earlier review on the coordination chemistry of thiadiazoles, thiazoles and isothiazoles, isothiazole-metal complexes were given little more than one page, with only five papers on this topic being considered. ${ }^{155}$

\section{Conclusion}

The presented and summarized data, published mainly over the past 18 years, demonstrates the intensive development of isothiazole chemistry and highlights the rich potential of isothiazole derivatives both for organic synthesis and practical use.

New data on the design of isothiazole heterocycles and the synthesis of isothiazole derivatives has been considered from the standpoint of retrosynthetic analysis, which allows four rational approaches for the formation of the isothiazole rings to be distinguished: intramolecular cyclization, (4+1)-heterocyclization, (3+2)-heterocyclization and synthesis based on other heterocyclic compounds. Such classification enables a consistent and logical understanding of the available approaches to obtaining substituted isothiazoles, and in some cases, to predict the most rational synthetic methods thereof.

The largest part of the published information is covered in the section dedicated to the target functionalization of substituted isothiazoles. This data demonstrates the rich possibilities of the developed strategies for successive transformations of isothiazole derivatives. Chlorinated isothiazoles seem particularly promising as starting compounds in this regard.

The logical continuation of such functionalizations is a separate section devoted to biologically active isothiazoles. In recent years, a large number of molecules containing the isothiazole fragment have been proposed as bioactive substances capable of selectively conjugating with key enzyme sites. There are various strategies for the formation of such molecules, which have been illustrated in detail. The most common strategy is sequential multistep synthesis based on isothiazole cores with reactive substituents. This method is used for the synthesis of a number of isothiazoles possessing significant antimitogenic activity. Sufficiently high interest is represented by published data on isothiazoles that exhibit synergistic effects in compositions with known anticancer drugs and pesticides. It is hoped that the research in this field will continue to develop rapidly and will unite the efforts of both chemists and specialists in the fields of biochemistry and medicine.

A separate section is devoted to isothiazoles in the synthesis of transition-metal complexes and in metal-complex catalysis. There is a great future for research in this field of isothiazole chemistry, especially in the development of metal-complex catalysts for cross-coupling reactions. The data on the metal complexes of the isothiazole series was previously sparse and fragmentary, and information on their possible practical use had not been summarized. Much remains to be done in this area in terms of improving metal-complex catalysts for effective use in aqueous media ('green chemistry') and in finding appropriate methods for 
determining their structures. The biological activity of metal complexes of isothiazoles remains an almost untouched field of research.

We hope that the data presented and analyzed herein will serve as a stimulus for further studies in the field of isothiazole chemistry, and that it will be useful not only to those who work in the field of heterocyclic chemistry and medicinal chemistry, but also to all specialists in modern organic synthesis as an inspiration and a source of ideas for further research.

\section{Funding Information}

The publication has been prepared with the support of the "RUDN University Program 5-100".

\section{References}

(1) Devys, M.; Barbier, M.; Loiselet, I.; Rouxel, T.; Sarniguet, A.; Kollmann, A.; Bousquet, J.-F. Tetrahedron Lett. 1988, 29 , 6447.

(2) Soledade, M.; Pedras, C.; Smith, K. C. Phytochemistry 1997, 46, 833.

(3) Nakae, K.; Adachi, H.; Sawa, R.; Hosokawa, N.; Hatano, M.; Igarashi, M.; Nishimura, Y.; Akamatsu, Y.; Nomoto, A. J. Nat. Prod. 2013, 76, 510.

(4) Stratmann, K.; Belli, J.; Jensen, C. M.; Moore, R. E.; Patterson, G. M. L. J. Org. Chem. 1994, 59, 6279.

(5) Garozzo, A.; Stivala, A.; Tempera, G.; Castro, A. Antiviral Res. 2010, 88, 325

(6) Banerjee, A.; Yadav, P. S.; Bajpai, M.; Sangana, R. R.; Gullapalli, S.; Gudi, G. S.; Gharat, L. A. Bioorg. Med. Chem. Lett. 2012, 22, 3223.

(7) Lippa, B.; Morris, J.; Corbett, M.; Kwan, T. A.; Noe, M. C.; Snow, S. L.; Gant, T. G.; Mangiaracina, M.; Coffey, H. A.; Foster, B.; Knauth, E. A.; Wessel, M. D. Bioorg. Med. Chem. Lett. 2006, 16, 3444.

(8) Carlessi, L.; Buscemi, G.; Larson, G.; Hong, Z.; Wu, J. Z.; Delia, D. Mol. Cancer Ther. 2007, 6, 935.

(9) Coffey, K.; Blackburn, T. J.; Cook, S.; Golding, B. T.; Griffin, R. J.; Hardcastle, I. R.; Hewitt, L.; Huberman, K.; McNeill, H. V.; Newell, D. R.; Roche, C.; Ryan-Munden, C. A.; Watson, A.; Robson, C. N. PLoS One 2012, 7, e45539.

(10) Baerfacker, L.; Prechtl, S.; Siemeister, G.; Wengner, A. M.; Ackerstaff, J.; Nowak-Reppel, K.; Bader, B.; Lienau, P.; Stoeckigt, D. WO2014118186A1, 2014.

(11) Ge, Y. CN105254624A, 2016.

(12) Ambati, S. R.; Gudala, S.; Sharma, A.; Penta, S.; Reddy, V. L.; Bomma, Y.; Janapala, V. R.; Pola, S. J. Heterocycl. Chem. 2017, 54, 2333.

(13) Shintani, Y.; Niwa, M.; Monma, S.; Ishiyama, S.; Shigeta, Y.; Kamiyama, T.; Shimazawa, Y.; Okada, K. WO2015170775A1, 2015.

(14) Sui, Z.; Cai, C.; Zhang, X. US20140275179A1, 2014

(15) Zhang, X.; Cai, C.; Sui, Z.; Macielag, M.; Wang, Y.; Yan, W.; Suckow, A.; Hua, H.; Bell, A.; Haug, P.; Clapper, W.; Jenkinson, C.; Gunnet, J.; Leonard, J.; Murray, W. V. ACS Med. Chem. Lett. 2017, 8, 947.

(16) Bobbio, C.; Corsi, C.; Jeanmart, S. A. M.; Wendeborn, S. V. WO2012010567A1, 2012.
(17) Kudva N, N. U.; Vicas, C. S.; Murthy, V. S.; Kotian, S. Y.; Byrappa, K.; Lokantha Rai, K. M. J. Chem., Biol. Phys. Sci. Sect. A 2016, 6, 861-868.

(18) Kaizerman, J. A.; Gross, M. I.; Ge, Y.; White, S.; Hu, W.; Duan, J.X.; Baird, E. E.; Johnson, K. W.; Tanaka, R. D.; Moser, H. E.; Burli, R. W. J. Med. Chem. 2003, 46, 3914.

(19) Bürli, R. W.; Ge, Y.; White, S.; Baird, E. E.; Touami, S. M.; Taylor, M.; Kaizerman, J. A.; Moser, H. E. Bioorg. Med. Chem. Lett. 2002, 12, 2591.

(20) Zhang, Y. 104513213, 2015.

(21) Liu, G.; Furuta, K.; Nakajima, H.; Ozoe, F.; Ozoe, Y. Bioorg. Med. Chem. 2014, 22, 4637.

(22) Corsi, C.; Wendeborn, S. V.; Bobbio, C.; Kessabi, J.; Schneiter, P.; Grasso, V.; Haas, U. J. WO2010069877A1, 2010.

(23) Zong, G.-N.; Li, F.-Y.; Fan, Z.-J.; Mao, W.-T.; Song, H.-B.; Chen, L.; Zhu, Y.-J.; Xu, J.-H.; Song, Y.-Q.; Wang, J.-R. Chin. J. Struct. Chem. 2015, 34, 871 .

(24) Wu, Q.-F.; Zhao, B.; Fan, Z.-J.; Zhao, J.-B.; Guo, X.-F.; Yang, D.-Y.; Zhang, N.-L.; Yu, B.; Kalinina, T.; Glukhareva, T. RSC Adv. 2018, 8 , 39593.

(25) Bumagin, N. A.; Potkin, V. I. Russ. Chem. Bull. 2016, 2, 321.

(26) Potkin, V. I.; Bumagin, N. A.; Zelenkovskii, V. M.; Petkevich, S. K.; Zubenko, Yu. S.; Livantsov, M. V.; Belov, D. S. Dokl. Natl. Acad. Sci. Belarus 2011, 55, 52.

(27) Lider, E. V.; Potkin, V. I.; Lavrenova, L. G. Book of Abstracts, Sviridov Readings 2012, 6th International Conference on Chemistry and Chemical Education; Belarusian State University: Minsk/ Belarus, Apr 9-13, 2012; Publishing Center of BSU: Minsk, 2012, 72.

(28) Chakroborty, S.; Bhanja, C.; Jena, S. A. Heterocycl. Commun. 2013, 19, 79.

(29) Silva, A. M. S.; Tomé, A. C.; Pinho e Melo, T. M. V. D.; Elguero, J. Five-Membered Heterocycles: 1,2-Azoles. Part 2. Isoxazoles and Isothiazoles, In Modern Heterocyclic Chemistry, Vol. 2; AlvarezBuilla, J.; Jose Vaquero, J.; Barluenga, J., Ed.; Wiley-VCH: Weinheim, 2011, 727-808.

(30) Wu, Y.-J.; Yang, B. V. Prog. Heterocycl. Chem. 2011, 22, 259.

(31) Brown, D. W.; Sainsbury, M. Isothiazoles, In Hetarenes and Related Ring Systems: Science of Synthesis Category 2, Vol. 11; Schaumann, E., Ed.; Georg Thieme Verlag: Stuttgart, 2002, 507572.

(32) Kaberdin, R. V.; Potkin, V. I. Russ. Chem. Rev. 2002, 71, 673.

(33) Clerici, F.; Gelmi, M. L.; Pellegrino, S. Compr. Heterocycl. Chem. 2008, 4, 543.

(34) Hamad Elgazwy, A.-S. S. Tetrahedron 2003, 59, 7445.

(35) Clerici, F.; Gelmi, M. L.; Pellegrino, S.; Pocar, D. Top. Heterocycl. Chem. 2007, 9, 179.

(36) Maienfisch, P.; Edmunds, A. J. F. Adv. Heterocycl. Chem. 2017, $121,35$.

(37) Schnürch, F.; Flasik, R.; Khan, A. F.; Spina, M.; Mihovilovic, M. D.; Stanetty, P. Eur. J. Org. Chem. 2006, 3283.

(38) Schulze, B.; Gidon, D.; Siegemund, A.; Rodina, L. L. Heterocycles 2003, 61, 639 .

(39) Hackler, R. E.; Burow, K. W. Jr.; Kaster, S. V.; Wickiser, D. I. J. Heterocycl. Chem. 1989, 26, 1575.

(40) Fisher, M. J.; Backer, R. T.; Barth, V. N.; Garbison, K. E.; Gruber, J. M.; Heinz, B. A.; Iyengar, S.; Hollinshead, S. P.; Kingston, A.; Kuklish, S. L.; Li, L.; Nisenbaum, E. S.; Peters, S. C.; Phebus, L.; Simmons, R. M. A.; van der Aar, E. Bioorg. Med. Chem. Lett. 2012, 22, 2514.

(41) Mishra, M.; Dutta Chowdhury, S. K.; Mahalanabis, K. K. Synth. Commun. 2004, 34, 2681. 
(42) Yan, S.; Appleby, T.; Gunic, E.; Shim, J. H.; Tasu, T.; Kim, H.; Rong, F.; Chen, H.; Hamatake, R.; Wu, J. Z.; Hong, Z.; Yao, N. Bioorg. Med. Chem. Lett. 2007, 17, 28.

(43) Larson, G.; Yan, S.; Chen, H.; Rong, F.; Hong, Z.; Wu, J. Z. Bioorg. Med. Chem. Lett. 2007, 17, 172.

(44) El Abdellaoui, H.; Varaprasad, C. V. N. S.; Barawkar, D.; Chakravarty, S.; Maderna, A.; Tam, R.; Chen, H.; Allan, M.; Wu, J. Z.; Appleby, T.; Yan, S.; Zhang, W.; Lang, S.; Yao, N.; Hamatake, R.; Hong, Z. Bioorg. Med. Chem. Lett. 2006, 16, 5561.

(45) Mishra, M.; Mahalanabis, K. K. ChemInform 2007, 38, 204.

(46) Kiselyov, A. S.; Semenova, M.; Semenov, V. V. Bioorg. Med. Chem. Lett. 2009, 19, 1195.

(47) Tang, Y.; Zhu, J.; Sun, T.; Wang, M.; Ding, J.; Tian, L.; Zhu, L.; Hong, C. CN103880774A, 2014.

(48) Bardasov, I. N.; Golubev, R. V.; Ershov, O. V.; Kayukov, Y. S.; Nasakin, O. E. Tetrahedron Lett. 2011, 52, 4724.

(49) Degl'Innocenti, A.; Funicello, M.; Scafato, P.; Spagnolo, P. Chem. Lett. 1994, 23, 1873.

(50) Capperucci, A.; Degl'Innocenti, A.; Scafato, P.; Spagnolo, P. Chem. Lett. 1995, 24, 147.

(51) Konstantinova, L. S.; Bastrakov, M. A.; Starosotnikov, A. M.; Glukhov, I. V.; Lysov, K. A.; Rakitin, O. A.; Shevelev, S. A. Mendeleev Commun. 2010, 20, 353.

(52) Abe, T. WO2014054294A1, 2014.

(53) Liu, B.-B.; Bai, H.-W.; Liu, H.; Wang, S.-Y.; Ji, S.-J. J. Org. Chem. 2018, 83, 10281.

(54) Shukla, G.; Srivastava, A.; Singh, M. S. Org. Lett. 2016, 18, 2451.

(55) Soni, S.; Koley, S.; Singh, M. S. Tetrahedron Lett. 2017, 58, 2512.

(56) Pedras, M. S. C.; Suchy, M. Bioorg. Med. Chem. 2006, 14, 714.

(57) Scholz, M.; Ulbrich, H. K.; Soehnlein, O.; Lindbom, L.; Mattern, A.; Dannhardt, G. Bioorg. Med. Chem. 2009, 17, 558.

(58) Amirhamzeh, A.; Vosoughi, M.; Shafiee, A.; Amini, M. Med. Chem. Res. 2013, 22, 1212.

(59) Zeng, L. F.; Zhang, H.-S.; Wang, Y.-H.; Sanchez, T.; Zheng, Y.-T.; Neamatic, N.; Long, Y.-Q. Bioorg. Med. Chem. Lett. 2008, 18, 4521.

(60) Fordyce, E. A. F.; Morrison, A. J.; Sharp, R. D.; Paton, R. M. Tetrahedron 2010, 66, 7192.

(61) Yanagida, Y.; Yazaki, R.; Kumagai, N.; Shibasaki, M. Angew. Chem. Int. Ed. 2011, 50, 7910.

(62) Clerici, F.; Contini, A.; Gelmi, M. L.; Pocar, D. Tetrahedron 2003, 59, 9399.

(63) Amati, M.; Belviso, S.; D’Auria, M.; Lelj, F.; Racioppi, R.; Viggiani, L. Eur. J. Org. Chem. 2010, 18, 3416.

(64) Seo, B.; Kim, Y. G.; Lee, P. H. Org. Lett. 2016, 18, 5050.

(65) Seo, B.; Kim, H.; Kim, Y. G.; Baek, Y.; Um, K.; Lee, P. H. J. Org. Chem. 2017, 82, 10574.

(66) Kalogirou, A. S.; Christoforou, I. C.; Ioannidou, H. A.; Manos, M. J.; Koutentis, P. A. RSC Adv. 2014, 4, 7735.

(67) Chappell, B.; Dedman, N.; Wheeler, S. Tetrahedron Lett. 2011, 52, 3223.

(68) Zlotin, S. G.; Kislitsyn, P. G.; Lukjanov, O. A. Russ. Chem. Bull. 1998, 47, 534.

(69) Nutaitis, C. Top. Heterocycl. Chem. 2012, 29, 329.

(70) Casoni, A.; Clerici, F.; Contini, A.; Pellegrino, S.; Sala, A. Lett. Org. Chem. 2008, 5, 623.

(71) Casoni, A.; Celentano, G.; Clerici, F.; Contini, A.; Gelmi, M. L.; Mazzeo, G.; Pellegrino, S.; Rosini, C. Tetrahedron: Asymmetry 2009, 20, 2247.

(72) Christoforou, I. C.; Koutentis, P. A.; Rees, C. W. Org. Biomol. Chem. 2003, 1, 2900.

(73) Ioannidou, H. A.; Koutentis, P. A. Org. Lett. 2011, 13, 1510.

(74) Kalogirou, A. S.; Koutentis, P. A. Tetrahedron 2014, 70, 7092.
(75) Potkin, V. I.; Zubenko, Yu. S.; Petkevich, S. K. Russ. J. Org. Chem. 2008, 44, 1211.

(76) Potkin, V. I.; Nechai, N. I.; Kaberdin, R. V. Russ. J. Org. Chem. 2007, 43, 587.

(77) Zubenko, Yu. S.; Kletskov, A. V.; Potkin, V. I.; Zvereva, T. D.; Zhukovskaya, N. A.; Zolotar, N. M.; Chepik, O. P. Proc. Natl. Acad. Sci. Belarus, Chem. Ser. 2011, 4, 53.

(78) Zubenko, Y.; Potkin, V. Synthesis 2009, 2361.

(79) Nechai, N. I.; Dikusar, E. A.; Potkin, V. I.; Kaberdin, R. V. Russ. J. Org. Chem. 2004, 40, 1050

(80) Potkin, V. I.; Dikusar, E. A.; Kletskov, A. V.; Petkevich, S. K.; Semenova, E. A.; Kolesnik, I. A.; Zvereva, T. D.; Zhukovskaya, N. A.; Rosentsveig, I. B.; Levkovskaya, G. G.; Zolotar, R. M. Russ. J. Gen. Chem. 2016, 86, 338.

(81) Belykh, D. V.; Malshakova, M. V.; Kletskov, A. V.; Ivanova, E. S.; Dutikova, Y. V.; Potkin, V. I.; Shtil, A. A. Macroheterocycles 2018, $11,269$.

(82) Potkin, V. I.; Petkevich, S. K.; Zubenko, Yu. S.; Bykhovets, A. I. Russ. J. Org. Chem. 2007, 43, 1532.

(83) Kletskov, A. V.; Kolesnik, I. A.; Dikusar, E. A.; Zhukovskaya, N. A.; Potkin, V. I. Russ. J. Gen. Chem. 2017, 87, 1167.

(84) Potkin, V. I.; Bykhovets, A. I.; Kaberdin, R. V.; Goncharuk, V. M.; Nechai, N. I.; Zolotar, N. M. BY 11556, 2009.

(85) Potkin, V. I.; Bykhovets, A. I.; Nechai, N. I.; Zolotar, N. M.; Petkevich, S. K.; Goncharuk, V. M. BY 11593, 2009.

(86) Potkin, V. I.; Bykhovets, A. I.; Lahvich, F. A.; Nechai, N. I.; Zolotar, N. M.; Goncharuk, V. M.; Zubenko, Yu. S.; Vashkevich, E. V. BY 12039, 2009.

(87) Petkevich, S. K.; Dikusar, E. A.; Kletskov, A. V. Rosentsveig I. B.; Levkovskaya, G. G.; Zolotar, R. M.; Kurman, P. V.; Potkin, V. I. Russ. J. Gen. Chem. 2018, 88, 234.

(88) Vasilevskii, D. A.; Galinovskii, N. A.; Ol'Khovik, V. K.; Golovchenko, L. A.; Potkin, V. I.; Kletskov, A. V. Russ. J. Org. Chem. 2014, 50, 1033.

(89) Nikitin, A. Y.; Potkin, V. I.; Bazanova, L. P.; Levkovskaya, G. G.; Petkevich, S. K.; Kletskov, A. V. Disinfection Affairs 2014, 2, 23.

(90) Potkin, V. I.; Zubenko, Yu. S. Russ. J. Org. Chem. 2009, 45, 568.

(91) Potkin, V. I.; Zubenko, Yu. S.; Nechai, N. I.; Bykhovets, A. I.; Kurman, P. V. Russ. J. Org. Chem. 2008, 44, 1038.

(92) Zubenko, Yu. S.; Potkin, V. I.; Bykhovets, A. I.; Zolotar, R. M.; Goncharuk, V. M. Proc. Natl. Acad. Sci. Belarus, Chem. Ser. 2009, 4, 94.

(93) Potkin, V. I.; Kletskov, A. V.; Petkevich, S. K.; Zubenko, Y. S.; Chotyanovich, M. O.; Kulchitsky, V. A. Russ. J. Org. Chem. 2013, 49, 283.

(94) Zubenko, Y. S.; Potkin, V. I.; Bykhovets, A. I.; Zolotar, R. M.; Goncharuk, V. M. Dokl. Natl. Acad. Sci. Belarus 2012, 56, 69.

(95) Potkin, V. I.; Petkevich, S. K.; Kletskov, A. V.; Kolesnik, I. A.; Dikusar, E. A.; Rozentsveig, I. B.; Levkovskaya, G. G.; Nasirova, D. K.; Borisova, K. K.; Zubkov, F. I. Russ. J. Org. Chem. 2018, 54, 452.

(96) Ioannidou, H. A.; Koutentis, P. A. Tetrahedron 2009, 65, 7023.

(97) Beebe, J. S.; Jani, J. P.; Knauth, E.; Goodwin, P.; Higdon, C.; Rossi, A. M.; Emerson, E.; Finkelstein, M.; Floyd, E.; Harriman, S.; Atherton, J.; Hillerman, S.; Soderstrom, C.; Kou, K.; Gant, T.; Noe, M. C.; Foster, B.; Rastinejad, F.; Marx, M. A.; Schaeffer, T.; Whalen, P. M.; Roberts, W. G. Cancer Res. 2003, 63, 7301.

(98) Cohen, R. B.; Langer, C. J.; Simon, G. R.; Eisenberg, P. D.; Hainsworth, J. D.; Madajewicz, S.; Cosgriff, T. M.; Pierce, K.; Xu, H.; Liau, K.; Healey, D. Cancer Chemother. Pharmacol. 2007, 60, 81.

(99) Luyten, I.; De Winter, H.; Busson, R.; Lescrinier, T.; Creuven, I.; Durant, F.; Balzarini, J.; De Clercq, E.; Herdewijn, P. Helv. Chim. Acta 1996, 79, 1462. 
(100) Pasha, F. A.; Muddassar, M.; Joo Cho, S. Chem. Biol. Drug Des. 2009, 73, 292.

(101) Reddy, B. M.; Tanneeru, K.; Meetei, P. A.; Guruprasad, L. Chem. Biol. Drug Des. 2012, 79, 84.

(102) Teffera, Y.; Choquette, D.; Liu, J.; Colletti, A. E.; Hollis, L. S.; Lin, M. H. J.; Zhao, Z. Chem. Res. Toxicol. 2010, 23, 1743.

(103) Perrone, M. G.; Vitale, P.; Malerba, P.; Altomare, A.; Rizzi, R.; Lavecchia, A.; Di Giovanni, C.; Novellino, E.; Scilimati, A. ChemMedChem 2012, 7, 629.

(104) McGregor, D. N.; Corbin, U.; Swigor, J. E.; Cheney, L. C. Tetrahedron 1969, 25, 389.

(105) Hao, J.; Dehlinger, V.; Fivush, A. M.; Rudyk, H. C. E.; Britton, T. C.; Hollinshead, S. P.; Vokits, B. P.; Clark, B. P.; Henry, S. S.; Massey, S. M.; Peng, L.; Dressman, B.; Heinz, B. A.; Roberts, E. F.; BraceyWalker, M. R.; Swanson, S.; Catlow, J. T.; Love, P. L.; Tepool, A. D.; Peters, S. C.; Simmons, R. M.; Iyengar, S.; McKinzie, D. L.; Monn, J. A. Bioorg. Med. Chem. Lett. 2013, 23, 1249.

(106) Britton, T. C.; Dehlinger, V.; Fivush, A. M.; Hollinshead, S. P.; Vokits, B. P. WO2009123855A1, 2009.

(107) Kiselyov, A. S.; Semenova, M. N.; Chernyshova, N. B.; Leitao, A.; Samet, A. V.; Kislyi, K. A.; Raihstat, M. M.; Oprea, T.; Lemcke, H.; Lantow, M.; Weiss, D. G.; Ikizalp, N. N.; Kuznetsov, S. A.; Semenov, V. V. Eur. J. Med. Chem. 2010, 45, 1683.

(108) Potkin, V. I.; Zubenko, Y.; Bykhovetz, A.; Zolotar, R.; Goncharuk, V. Nat. Prod. Commun. 2009, 4, 1205.

(109) Potkin, V. I.; Kletskov, A. V.; Petkevich, S. K.; Zubenko, Y. S.; Dikusar, E. A.; Zvereva, T. D.; Zolotar, R.; Chepik, O. P. Dokl. Natl. Acad. Sci. Belarus 2013, 57, 76.

(110) Kletskov, A. V.; Potkin, V. I.; Dikusar, E. A.; Zolotar, R. M. Nat. Prod. Commun. 2017, 12, 105.

(111) Kletskov, A. V.; Potkin, V. I.; Kolesnik, I. A.; Petkevich, S. K.; Kvachonak, A. V.; Dosina, M. O.; Loiko, D. O.; Larchenko, M. V.; Pashkevich, S. G.; Kulchitsky, V. A. Nat. Prod. Commun. 2018, 13, 1507.

(112)Yu, T.; Tagat, J. R.; Kerekes, A. D.; Doll, R. J.; Zhang, Y.; Xiao, Y.; Esposite, S.; Belanger, D. B.; Curran, P. J.; Mandal, A. K.; Siddiqui, M.; Shih, N.; Basso, A.; Liu, M.; Gray, K.; Tevar, S.; Jones, J.; Lee, S.; Liang, L.; Ponery, S.; Smith, E.; Hruza, A.; Voigt, J.; Ramanathan, L.; Prosise, W.; Hu, M. ACS Med. Chem. Lett. 2010, $1,214$.

(113) Kulchitsky, V. A.; Potkin, V. I.; Zubenko, Y. S.; Chernov, A. N.; Talabaev, M. V.; Demidchik, Y. E.; Petkevich, S. K.; Kazbanov, V. V.; Gurinovich, T. A.; Roeva, M. O.; Grigoriev, D. G.; Kletskov, A. V.; Kalunov, V. N. Med. Chem. 2012, 8, 22.

(114) Potkin, V. I.; Petkevich, S. K.; Kletskov, A. V.; Zubenko, Yu. S.; Kurman, P. V.; Pashkevich, S. G.; Gurinovich, T. A.; Kulchitskiy, V. A. Russ. J. Org. Chem. 2014, 50, 1667.

(115) Potkin, V. I.; Kletskov, A. V.; Petkevich, S. K.; Paschkevich, S. G.; Kazbanov, V. V.; Denisov, A. A.; Kulchitsky, V. A. Heterocycl. Lett. 2015, 1,11 .

(116) Sharma, A.; Suhas, R.; Gowda, D. C. Arch. Pharm. 2013, 346, 359.

(117) Reddy, K. I.; Srihari, K.; Renuka, J.; Sree, K. S.; Chuppala, A.; Jeankumar, V. U.; Sridevi, J. P.; Babu, K. S.; Yogeeswari, P.; Sriram, D. Bioorg. Med. Chem. 2014, 22, 6552.

(118) Ross, J. F.; Delipala, C.; Watson, M. C.; Crosby, J.; Paton, R. M. ARKIVOC 2013, (iii), 372

(119) Pedras, M. S. C.; Jha, M. J. Org. Chem. 2005, 70, 1828.

(120) Bezbaruah, P.; Gogoi, J.; Rao, K. S.; Gogoi, P.; Boruah, R. C. Tetrahedron Lett. 2012, 53, 4389.

(121) Vicentini, C. B.; Poli, T.; Manfrini, M.; Guarneri, M.; Giori, P.; Brandolini, V. Farm. Ed. Sci. 1987, 42, 133.

(122) Vicentini, C. B.; Romagnoli, C.; Manfredini, S.; Rossi, D.; Mares, D. Pharm. Biol. 2011, 49, 545.
(123) Rossi, D.; Mares, D.; Romagnoli, C.; Andreotti, E.; Manfredini, S.; Vicentini, C. B. Drug Chem. Toxicol. 2011, 34, 324.

(124) Koyioni, M.; Manoli, M.; Manolis, M. J.; Koutentis, P. A. J. Org. Chem. 2014, 79, 4025.

(125) L'abbé, G.; D’hooge, B.; Dehaen, W. J. Chem. Soc., Perkin Trans. 1 1995, 2379.

(126) Rivest, R.; Weisz, A. Can. J. Chem. 1971, 49, 1750.

(127) Peach, M. E.; Ramaswamy, K. K. Inorg. Chim. Acta 1971, 5, 445.

(128) Sinha, A. I. P.; Jain, J. L. J. Inorg. Nucl. Chem. 1981, 43, 3384.

(129) Sinha, A. I. P.; Jain, J. L.; Sinha, B. K. Synth. React. Inorg. Met.-Org. Chem. 1984, 14, 151.

(130)Sinha, A. I. P.; Tewari, S. P.; Sinha, B. K. Vijnana Parishad Anusandhan Patrika 1989, 32, 17.

(131) Gruschinski, S.; Handke, M.; Kersting, B. Z. Anorg. Allg. Chem. 2012, 638, 1274.

(132) Kulig, J.; Lenarcik, B. Pol. J. Chem. 1978, 52, 477.

(133) Singh, P. P.; Srivastava, A. K.; Pathak, L. P. J. Coord. Chem. 1979, 9, 65.

(134) Singh, P. P.; Pathak, L. P.; Srivastava, S. K. J. Inorg. Nucl. Chem. 1980, 42, 533.

(135)Weis, J. C.; Beck, W. J. Organomet. Chem. 1972, 44, 325.

(136) Pannell, K. H.; Lee, C. C.-Y.; Párkányi, C.; Redfearn (né Snow), R. Inorg. Chim. Acta 1975, 12, 127.

(137) Hartshorn, R. M.; Willis, A. C.; Sargeson, A. M. J. Chem. Soc., Chem. Commun. 1988, 18, 1269.

(138) Konrad, M.; Meyer, F.; Büchner, M.; Heinze, K.; Zsolnai, L. Chem. Ber. 1997, 130, 95.

(139) Potkin, V. I.; Lavrenova, L. G.; Lider, E. V.; Petkevich, S. K.; Zubenko, Y. S.; Kletskov, A. V.; Zolotar, R.; Timofeeva, V. A.; Golovchenko, L. A.; Book of Abstracts, 25th International Chugaev Conference on Coordination Chemistry, Suzdal, Russia, Jun 6-11, 2011; 'Ivanovo' Publishing: Russia, 2011, 398.

(140) Lider, E. V.; Ikorskij, V. N.; Potapov, A. S.; Khlebnikov, A. I.; Zubenko, Y. S.; Potkin, V. I.; Lavrenova, L. G.; Book of Abstracts, 24th International Chugaev Conference on Coordination Chemistry, St. Petersburg, Russia, Jun 15-19, 2009; Russkij Zapad; ISBN 5-85263-026-8: St. Petersburg, 2009, 103.

(141) Potkin, V. I.; Kletskov, A. V.; Lider, E. V.; Lavrenova, L. G.; Zolotar, R. Dokl. Natl. Acad. Sci. Belarus 2016, 60, 86.

(142) King, A. O.; Yasuda, N. Palladium-Catalyzed Cross-Coupling Reactions in the Synthesis of Phrmaceuticals, In Topics in Organometallic Chemistry, Vol. 6; Larsen, R. D., Ed.; Springer-Verlag: Berlin, 2004, 205-245.

(143) Lightowler, S.; Hird, M. Chem. Mater. 2004, 16, 3963.

(144) Johansson Seechurn, C. C. C.; Kitching, M. O.; Colacot, T. J.; Snieckus, V. Angew. Chem. Int. Ed. 2012, 51, 5062.

(145) Bellina, F.; Carpita, A.; Rossi, R. Synthesis 2004, 2419.

(146) Yin, L.; Liebscher, J. Chem. Rev. 2007, 107, 133.

(147) Polshettiwar, V.; Decottignies, A.; Len, C.; Fihri, A. ChemSusChem 2010, 3, 502.

(148) Chatterjee, A.; Ward, T. R. Catal. Lett. 2016, 146, 820.

(149) Potkin, V. I.; Bumagin, S. K.; Petkevich, S. K.; Kletskov, A. V.; Zubenko, Y. S.; Golantsov, N. E.; Livantsov, M. V.; Belov, D. S.; Veselov, I. S. Dokl. Natl. Acad. Sci. Belarus 2013, 57, 67.

(150) Bumagin, N. A.; Petkevich, S. K.; Kletskov, A. V.; Livantsov, M. V.; Golantsov, N. E.; Potkin, V. I. Chem. Heterocycl. Compd. 2013, 10, 1633.

(151) Bumagin, N. A.; Petkevich, S. K.; Kletskov, A. V.; Potkin, V. I. Chem. Heterocycl. Compd. 2017, 53, 1340.

(152) Kletskov, A. V.; Bumagin, N. A.; Petkevich, S. K.; Zvereva, N. A.; Zhukovskaya, P. V.; Kurman, P. V.; Potkin, V. I. Proc. Natl. Acad. Sci. Belarus, Chem. Ser. 2015, 2, 54. 
(153) Bumagin, N. A.; Zelenkovskii, V. M.; Kletskov, A. V.; Petkevich, S. K.; Dikusar, E. A.; Potkin, V. I. Russ. J. Gen. Chem. 2016, 86, 68.

(154) Bumagin, N. A.; Dikusar, E. A.; Kletskov, A. V.; Petkevich, S. K.; Potkin, V. I. Proc. Natl. Acad. Sci. Belarus, Chem. Ser. 2015, 4, 34.
(155) Frija, L. M. T.; Pombeiro, A. J. L.; Kopylovich, M. N. Coord. Chem. Rev. 2016, 308, 32 